\title{
Aportaciones hidrogeológicas al estudio arqueológico de los orígenes de la Edad del Bronce de La Mancha: la cueva monumentalizada de Castillejo del Bonete (Terrinches, Ciudad Real, España)
}

\author{
Hydrogeological contributions to the archaeological study of the origins of the Bronze Age \\ of La Mancha: the monumentalised cave of Castillejo del Bonete (Terrinches, Ciudad \\ Real, Spain)
}

\author{
Luis Benítez de Lugo Enrich (*) \\ Miguel Mejías Moreno (**) \\ Julio López Gutiérrez (**) \\ Honorio Javier Álvarez García (***) \\ Norberto Palomares Zumajo (***) \\ Enrique Mata Trujillo (***) \\ Jaime Moraleda Sierra (***)
}

\author{
Gabriel Menchén Herreros $(* * *)$ \\ Sergio Fernández Martín (****) \\ Domingo Carlos Salazar-García (*****) \\ Carlos Odriozola Lloret (******) \\ María Benito Sánchez $(* * * * * *)$ \\ José Antonio López Sáez (******)
}

\section{RESUMEN}

Estudios recientes indican que las motillas, asentamientos de la Edad del Bronce de La Mancha, pudieron

(*) Departamento de Arqueología y Prehistoria, UNED. 13300 Valdepeñas. Ciudad Real. España. Correo e.: lbenitez@valdepenas.uned.es

(**) Área de Infraestructura Hidrogeológica, Departamento de Investigación y Prospectiva Geocientífica. Instituto Geológico y Minero de España. C/ Ríos Rosas 23. 28003 Madrid. España. Correos e.: m.mejias@igme.es; j.lopezgu@igme.es

(***) Anthropos s.l. 13300 Valdepeñas. Ciudad Real, España. Correo e.: anthropos@estudio-arqueologia.es

(****) Arqueólogo profesional. C/ Noguera del Manco 2, 3. ${ }^{\circ}, 19.18160$ Guéjar Sierra. Granada. España.

Correo e.: sfcalar@yahoo.es

$(* * * * *)$ Department of Human Evolution, Max-Planck Institute for Evolutionary Anthropology. Deutscher Platz 6. 04103 Leipzig. Alemania, Department of Archaeology, University of Capetown, Departamento de Prehistoria y Arqueología, Universidad de Valencia. Correo e.: domingo_carlos@eva.mpg.de

(******) Departamento de Prehistoria y Arqueología, Universidad de Sevilla. C/ María de Padilla s/n. 41004 Sevilla. España. Correo e.: codriozola@us.es

$(* * * * * * *)$ Laboratorio de Antropología Forense, Facultad de Medicina, Universidad Complutense de Madrid, Ciudad Universitaria s/n. 28040 Madrid. España.

Correo e.: m.benito.sanchez@gmail.com

$(* * * * * * * *)$ Grupo de Investigación "Arqueobiología". Instituto de Historia, Centro de Ciencias Humanas y Sociales (CCHS), Consejo Superior de Investigaciones Científicas (CSIC). C/ Albasanz 26-28. 28037 Madrid. España.

Correo e.: joseantonio.lopez@cchs.csic.es ser las más antiguas captaciones de agua subterránea en la Península Ibérica. Pero ¿por qué no existen motillas en el Campo de Montiel, territorio ubicado tradicionalmente en esta área cultural? En Castillejo del Bonete, sitio arqueológico situado en esa comarca, existe una cueva que fue utilizada y sellada durante la Prehistoria Reciente. Se presenta ahora la primera investigación paleohidrogeológica interdisciplinar en La Mancha, que ha analizado manantiales y niveles de agua subterránea del acuífero de Campo de Montiel, así como el interior de la sima de Castillejo del Bonete. Las conclusiones avanzan una relación entre el sustrato hidrogeomorfológico y la distribución espacial de las motillas. Además permiten descartar que la sima de Castillejo del Bonete fuera utilizada como mina o como acceso al acuífero, dos de las hipótesis de trabajo planteadas. De ese modo cobra fuerza que Castillejo del Bonete fuera un excepcional monumento funerario $\mathrm{y}$ simbólico durante el Calcolítico y la Edad del Bronce, perteneciente a una nueva clase de asentamientos desconocidos hasta ahora en el grupo cultural de la Edad del Bronce de La Mancha.

\footnotetext{
ABSTRACT

Recent studies show that the motillas of the Bronze Age in La Mancha contain the oldest wells in the Iberian Peninsula. But why are there no motillas in Campo de Montiel, a territory traditionally placed inside this cultural area? In Castillejo del Bonete, an archaeological site located in Campo de Montiel, there is a
} 
cave used and sealed during Late Prehistory. We here report the first paleohidrogeological interdisciplinary research in La Mancha, analyzing some spring and freatic levels from the Campo de Montiel aquifer, as well as from inside the Castillejo del Bonete chasm. Our findings suggest an association between the hydrogeological substrate and the spatial distribution of the motillas, discarding the idea that the chasm at Castillejo del Bonete could be a mine or an aquifer access. This supports the idea that Castillejo del Bonete was an exceptional symbolic monument during the Chalcolithic and the Bronze Age, within a new type of site of the cultural group of the Bronze Age of La Mancha.

Palabras clave: Prehistoria Reciente; Península Ibérica; Motilla; Monumento Tumular; Pozo; Holoceno; Acuífero; Caliza.

Key words: Late Prehistory; Iberian Peninsula; Motilla; Monumental Barrow; Well; Holocene; Aquifer; Limestone.

\section{INTRODUCCIÓN}

Las más recientes publicaciones acerca de la Cultura de la Edad del Bronce de La Mancha o Cultura de las Motillas (Fernández-Posse et al. 2008: 14-15; Benítez de Lugo 2010: 41, 2011a, 2011b) se hacen eco de las hipótesis que interpretaban su fósil director, la motilla, como una posible explotación hidráulica (Nájera y Molina 2004a, 2004b, 2004c; Molina et al. 2005; Nájera et al. 2006; Nájera et al. 2010; Aranda et al. 2008) (Fig. 1).

Las motillas son asentamientos fortificados cuya planta tiende al círculo y cuenta con doble o triple línea de muralla y, en ocasiones, con una torre central. Se sitúan en llanuras de inundación de ríos, en el centro de antiguas lagunas, en zonas endorreicas o allí donde el nivel freático resulta

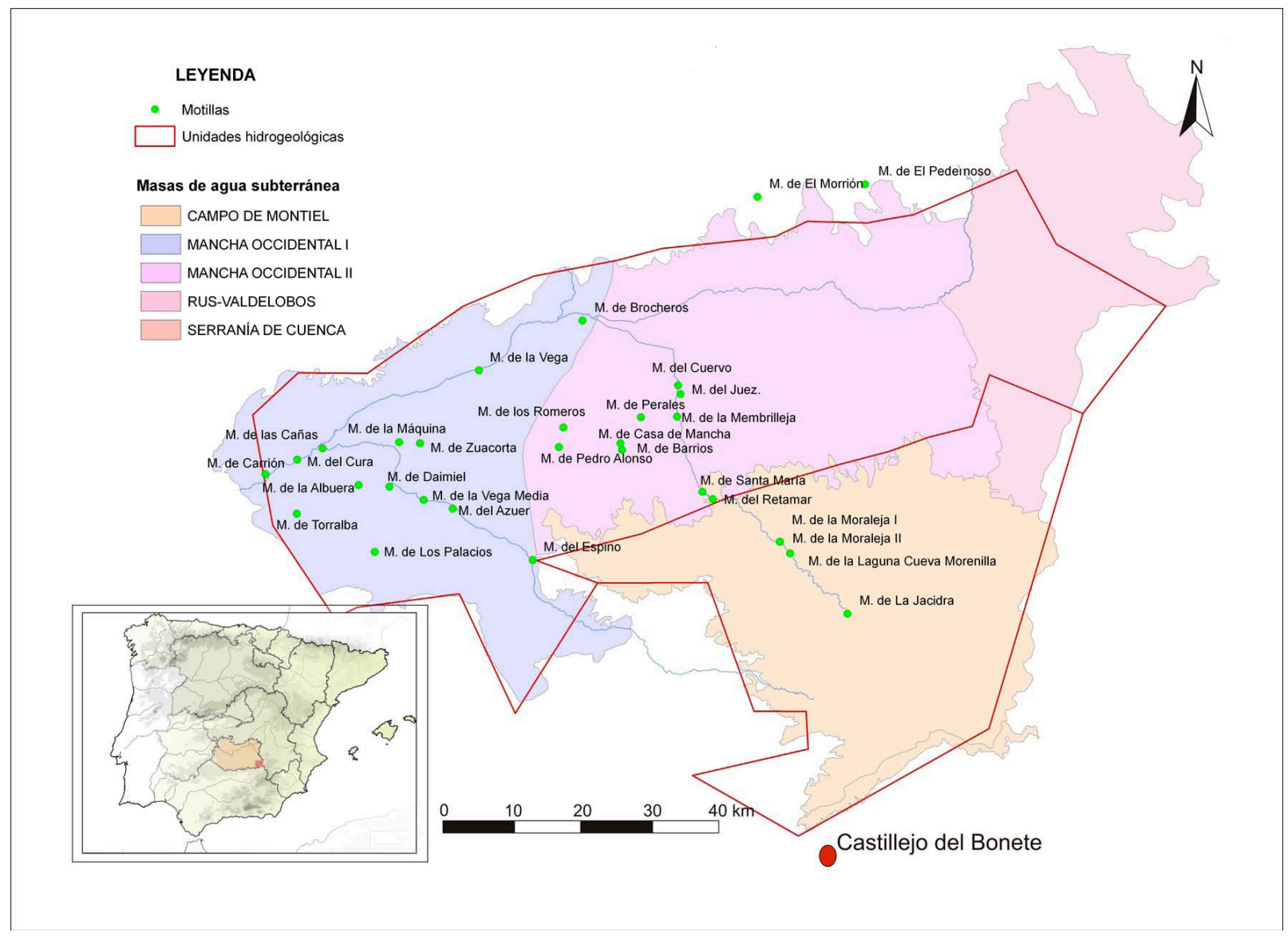

Fig. 1. Plano general de localización de Castillejo del Bonete y de las motillas (M) en relación a las Unidades Hidrogeológicas y las Masas de Agua Subterránea definidas en este estudio. 
más accesible. Son arquitecturas complejas de muros superpuestos cuya ruina ha llegado a formar verdaderos tells (García Pérez 1988; Fernández Miranda et al. 1993; Galán y Sánchez Meseguer 1994; Ruiz Taboada 1996; Benítez de Lugo y Mejías 2014; Mejías et al. e. p. 2014) (Fig. 2).
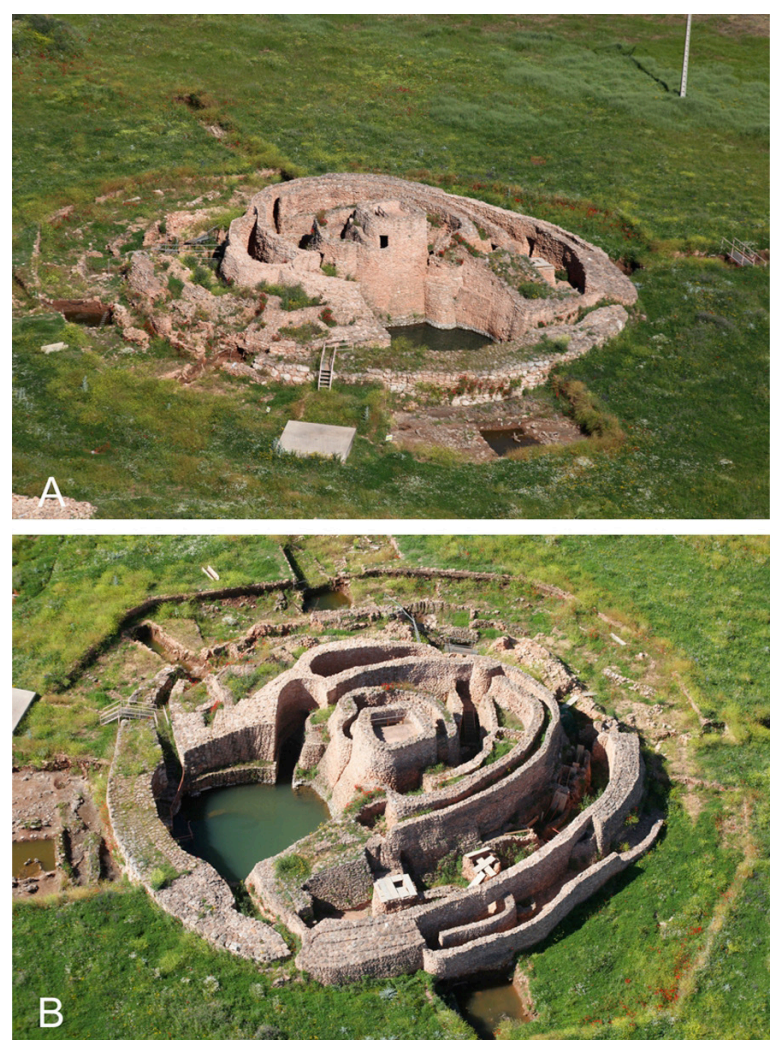

Fig. 2. Vistas aéreas generales lateral (A) y vertical (B) del gran pozo fortificado con torre y muralla en la Motilla del Azuer (Daimiel, Ciudad Real), en 2013, con el nivel freático por encima de los niveles inferiores del edificio (Fotografía (C) SAF Juan I. Rozas Blanco; propiedad IGME).

Las motillas se establecieron en lugares de fácil acceso al nivel freático y donde el agua no era salina (Fig. 3). No están necesariamente ligadas a cursos fluviales, aunque es notable la coincidencia de la proximidad del nivel freático del acuífero plioceno regional a la superficie. Probablemente, estos asentamientos funcionaron como lugares estratégicos de un territorio al que abastecían y en el que existían otros poblados coetáneos (en llano, en altura, etc.) con los que mantenían estrechas relaciones (Galán y Sánchez Meseguer 2007) (Fig. 4). El almacenamiento de
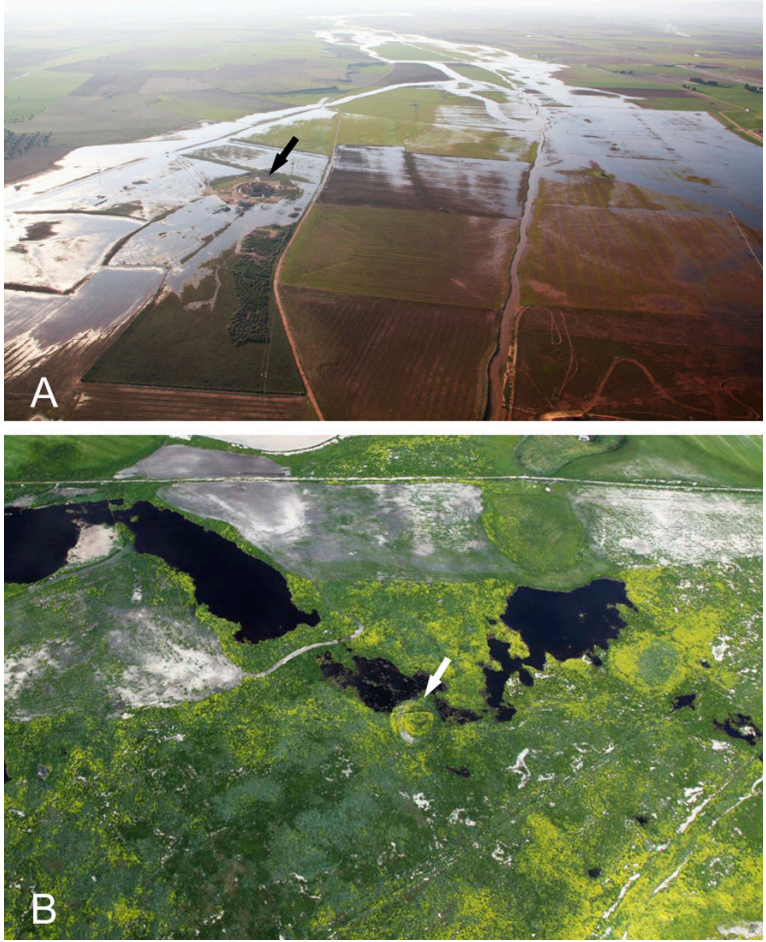

Fig. 3. Vistas generales de los entornos de dos motillas en Daimiel, Ciudad Real: la Motilla del Azuer, en 2010 (A) y la Motilla de Zuacorta junto al cauce del río Guadiana, en mayo de 2013 (B). Estos poblados prehistóricos fueron construidos y ocupados cuando las aguas superficiales prácticamente habían desaparecido. (Fotografías (C) SAF Juan I. Rozas Blanco; propiedad IGME).

cereales y el aprovisionamiento de agua parecen ser dos de sus funciones más relevantes (Aranda et al. 2008: 245; Benítez de Lugo 2011a: 148).

El área de influencia de los grupos de la Edad del Bronce de La Mancha y de sus motillas gira en torno a dos grandes núcleos, las Tablas de Daimiel y las Lagunas de Ruidera, establecidos entre las cuencas del río Guadiana y sus afluentes Záncara, Gigüela y Azuer, casi todos en la provincia de Ciudad Real. La Motilla del Acequión, construida dentro de la laguna homónima en el actual término municipal de Albacete, está desplazada $68 \mathrm{~km}$ al Este de su motilla más cercana, es decir, fuera de los dos núcleos citados (Fernández-Miranda et al. 1993; Fernández-Posse et al. 2008: 20, Fig. A, n. ${ }^{\circ}$ 61, p. 77). Esta motilla es muy relevante, entre otras cosas, por esa ubicación. Permite intuir que, durante la Edad del 


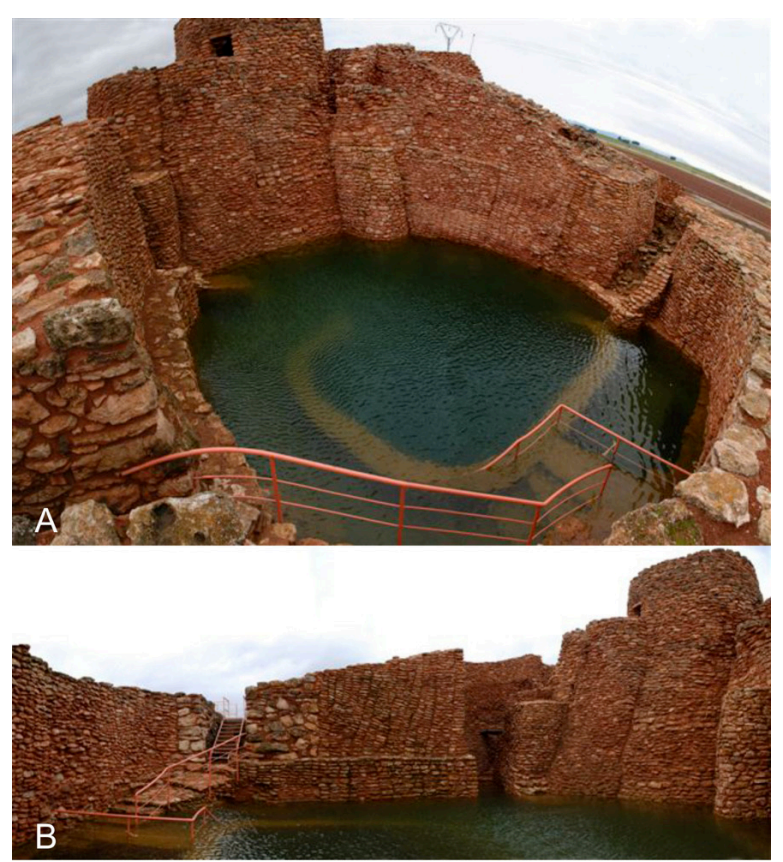

Fig. 4. Interior de la Motilla del Azuer (Daimiel, Ciudad Real). Vistas vertical (A) y lateral (B) del pozo. Las cotas alcanzadas por el nivel freático del acuífero en 2010 y 2011, de haber existido en la Edad del Bronce, habría impedido cualquier edificación. Los constructores de la motilla perforaron la roca en seco en busca del agua.

Bronce, toda la zona occidental de la provincia de Albacete, por la que se extiende parte del Campo de Montiel, debió encontrarse en la órbita de la Cultura de las Motillas. Los grupos humanos que la integraban no se asentaron solo en las proximidades de los cauces de los ríos o sobre los acuíferos regionales sino allí donde las características geológicas e hidrogeológicas del subsuelo, los niveles endorreicos y su tecnología lo permitían.

Cabe entonces preguntarse por qué en el Campo de Montiel, un espacio habitualmente ubicado en esa órbita cultural, hay motillas sobre el cauce del río Guadiana en el área de las Lagunas de Ruidera pero no en la cuenca del Jabalón, otro afluente del Guadiana (Fig. 5). Ambas cuestiones inciden de lleno en dos problemas todavía sin resolver, tras nada menos que tres décadas de investigación: los límites de la Cultura de las Motillas (Martínez Navarrete 1988) y la explicación de los patrones de localización de los asentamientos. Este trabajo supone un avance en ambos aspectos. Hasta el momento, faltaba un estudio que considerara la hidrogeología como la
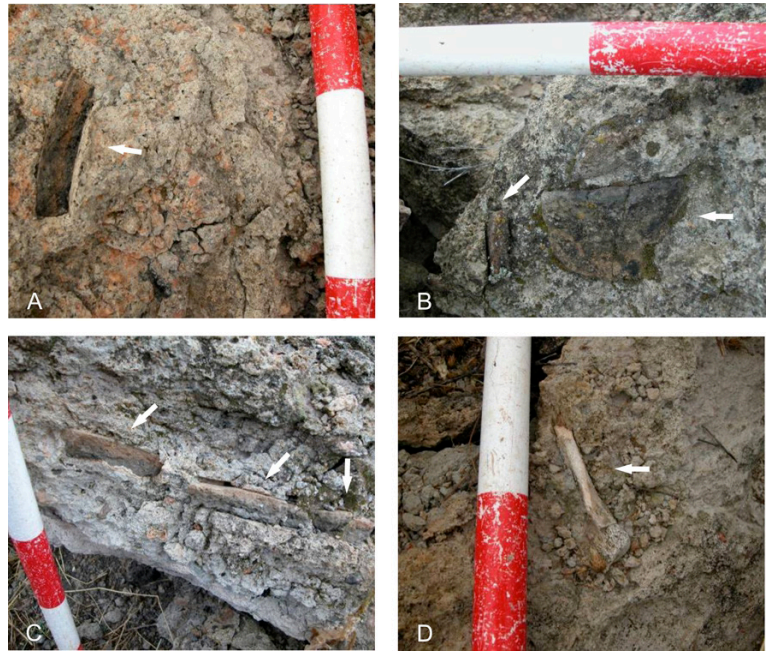

Fig. 5. Motilla de la Jacidra (Villahermosa, Ciudad Real) (localizada en Fig. 1): cerámicas (A-C) y hueso (D) incrustados en la roca tobácea. Las aguas del río Guadiana cubrieron el asentamiento tras la Edad del Bronce, petrificando los materiales arqueológicos.

variable principal para explicar el origen y desaparición de las motillas. Este artículo trata el tema en detalle y esclarece también el patrón de distribución de las mismas en el Campo de Montiel y su contraste con el de Castillejo del Bonete. Este yacimiento de tipología inédita, localizado también en esa comarca, se asienta en parte sobre una sima y no está relacionado con explotación hidráulica o geológica alguna.

\section{CASTILLEJO DEL BONETE}

Castillejo del Bonete es una prominencia situada en el borde meridional del Campo de Montiel al sureste de la provincia de Ciudad Real (Fig. 1). Probablemente la ubicación del yacimiento, cercano a otros de la misma época, tuvo en cuenta dos circunstancias: la existencia de una sima y las condiciones de visibilidad del lugar. La sima fue monumentalizada durante la Prehistoria Reciente construyendo sobre ella un complejo tumular con varios corredores (Fig. 6) (planta en Benítez de Lugo 2010: 31; Benítez de Lugo et al. e. p. 2014).

Desde la ladera orientada al Sur del emplazamiento hay una excelente relación visual con la denominada Vía de los Vasos de Vicarello (Benítez de Lugo et al. 2012; Sánchez Sánchez et al. 2012), un importante corredor natural de comu- 


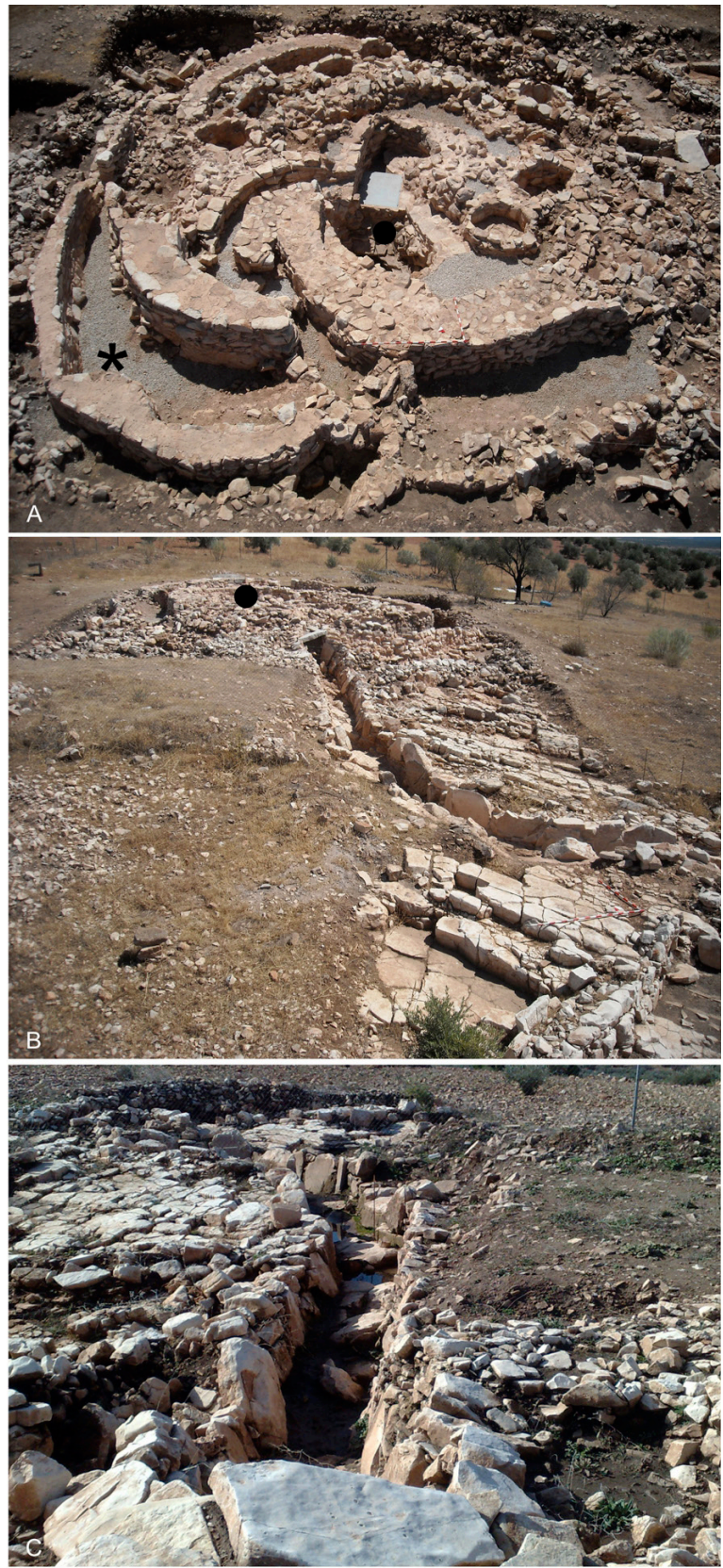

Fig. 6. Castillejo del Bonete (Terrinches, Ciudad Real), en 2012 (A y B vistas aéreas): A. Desde el Norte, edificaciones sobre el acceso a la cueva $(\bullet)$ con el recinto que albergaba la Tumba 4 (*). B. Desde el Oeste, corredor que se dirige a la cueva $(\bullet)$ y que comunica dos túmulos. C. Detalle del corredor con parte de la cubierta con losa caliza en primer término.

nicación entre Levante, la Submeseta Sur y la Alta Andalucía. La situación de los yacimientos de la Prehistoria Reciente en lugares estratégicos claramente se relaciona con ese corredor que da paso hacia el Sur a Sierra Morena y la Alta Andalucía y sigue un patrón ya detectado en Sierra Morena (Murrieta-Flores 2012). Cabe recordar la vinculación de los túmulos prehistóricos a los pasos ganaderos de ambas Mesetas (Bueno 1990: 148; López Saéz 2011: 287). Sabemos también que, durante la Protohistoria, Sierra Morena no dividió las comunidades culturales, sino al contrario, aglutinó a los grupos oretanos septentrionales y meridionales en torno a santuarios étnicorurales como Collado de los Jardines y la Cueva de la Lobera-Los Altos del Sotillo.

Castillejo del Bonete se encuentra en el supuesto borde meridional de distribución de la Cultura de la Edad del Bronce de La Mancha, cuyas fronteras precisas, como recordaremos, están por definir. Es un yacimiento complejo y singular, donde se han documentado materiales arqueológicos de dilatada cronología. Destacamos los enterramientos con ajuares (Fig. 7) como 3 botones de marfil, decenas de útiles de cobre en excelente estado de conservación ( 5 cuchillos, 6 flechas del tipo Palmela -las únicas puntas de proyectil halladas- y numerosos punzones) (Montero et al. e. p. 2014) 31 cuentas de variscita (Fig. 8A) o 3 preformatos de moscovita de diferente procedencia, preparados para ser tallados. Predominan las cerámicas clásicas de los asentamientos de dicha cultura, pero hay depósitos con fragmentos decorados con soliformes e incisiones, característicos de fechas calcolíticas. Hay cerámicas campaniformes, en ocasiones, con decoraciones rellenas de pasta blanca elaborada con carbonato cálcico como suele ser frecuente en la Meseta (Odriozola et al. 2012). En las concreciones de alguno de los recipientes se ha identificado ácido acético, presente en productos como aceite, vino, bebidas alcohólicas que contengan etanol, etc. La muestra no contenía ácido tartárico, por lo que se debe descartar que contuvieran vino. Este hallazgo supone el posible uso, al menos de una parte de las cerámicas amortizadas en Castillejo del Bonete, para el consumo de bebidas alcohólicas.

Hay adornos personales y numerosos punzones fabricados con hueso (Fig. 9), así como molinos barquiformes con su mano y solera en posición primaria, una maza ofítica (Fig. $8 \mathrm{~B}$ ) e industria lítica tallada, adscribibles a tradiciones calcolíticas del III milenio a.n.e. Se han encontrado restos de fauna en Castillejo del Bonete, testimonio de posibles banquetes, así como partes de animales, depositadas enteras en el lugar, po-

Trab. prehist., 71, N. ${ }^{\circ}$ 1, enero-junio 2014, pp. 76-94, ISSN: 0082-5638

doi: $10.3989 /$ tp.2014.12125 


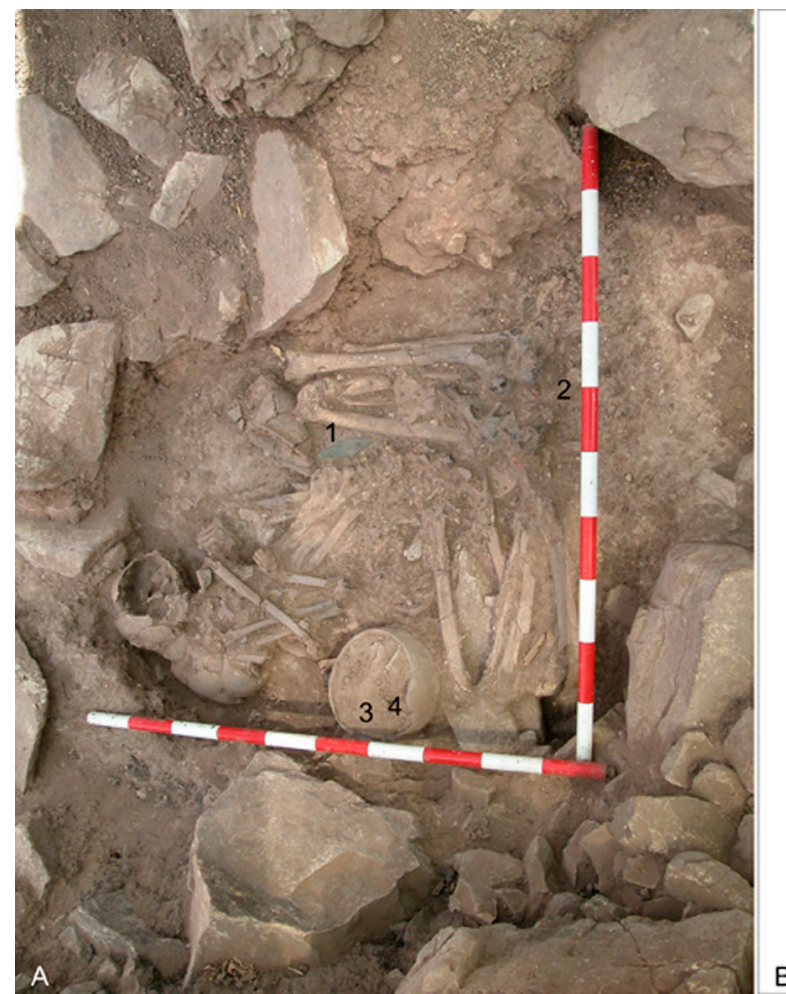

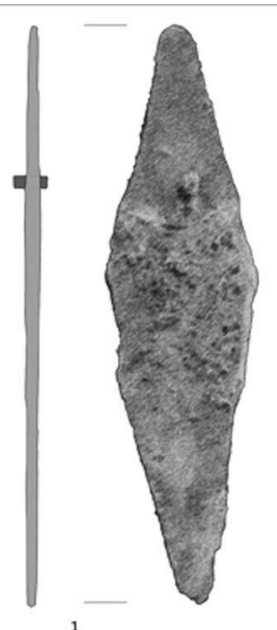

1 TE 04/8O/NC15/TUmbo 4

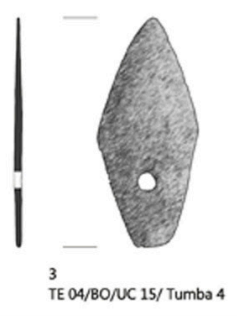

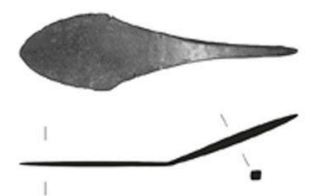

$\mid$

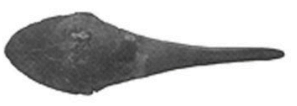

${ }_{\text {TE OA/BO/D10/UE6/ Tumbo } 4}^{2}$

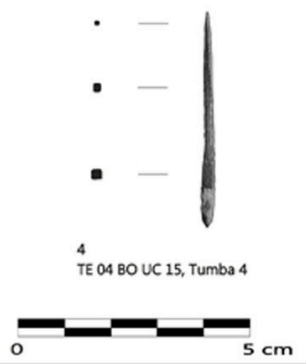

Fig. 7. Castillejo de Bonete (Terrinches, Ciudad Real), Tumba 4 (Fig. 6A*) y su ajuar. A. Sobre la inhumación doble se encendió una hoguera. Dos botones de marfil aparecieron junto al pecho de uno de los muertos. B. El ajuar metálico incluye: 1. puñal de remache, 3. cuchillo muy gastado, 4. aguja (en la olla globular) y 2. punta de flecha del tipo Palmela con el pedúnculo doblado (sobre la hoguera).

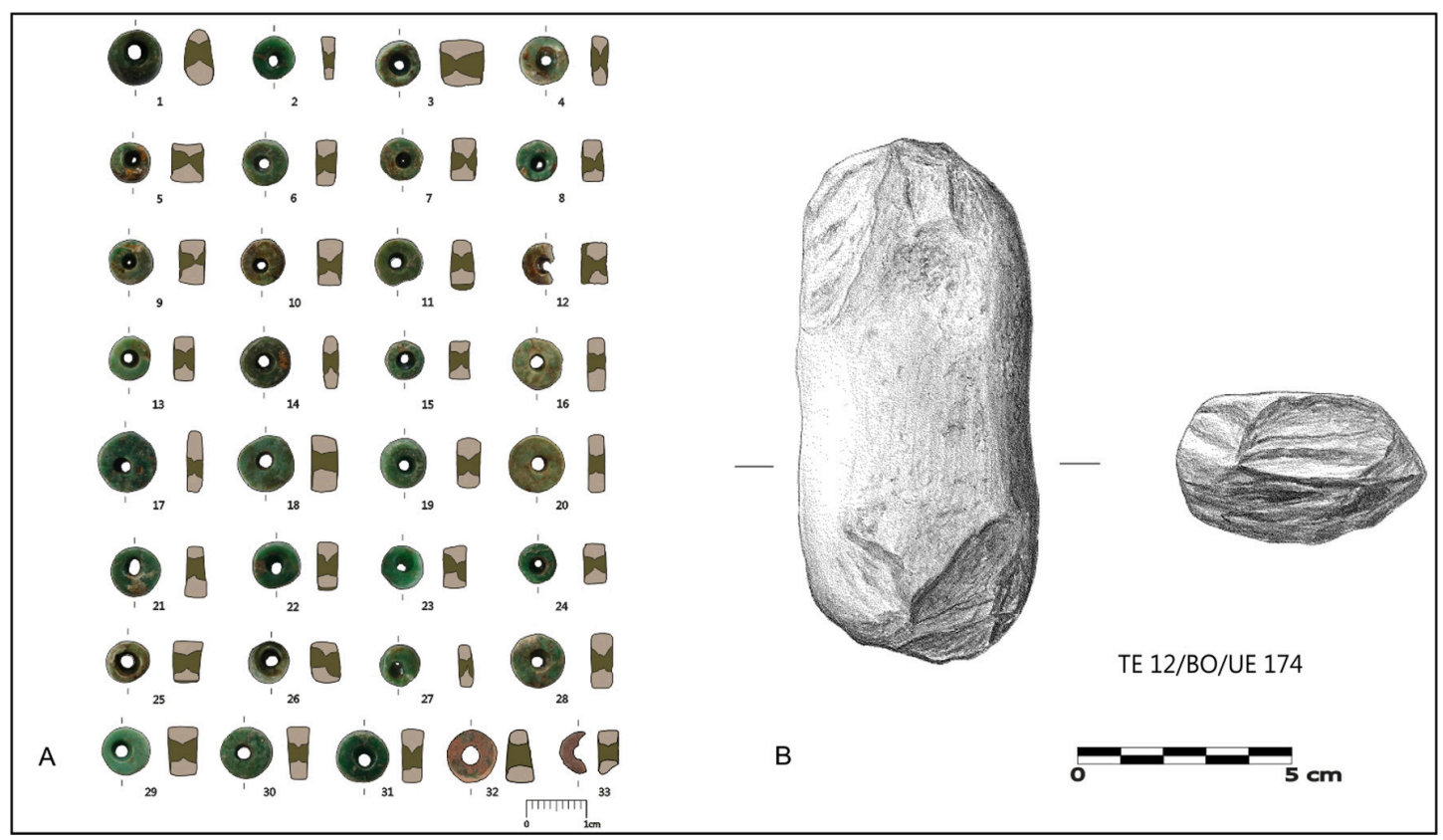

Fig. 8. Castillejo de Bonete (Terrinches, Ciudad Real). A. Cuentas de variscita depositadas junto a restos humanos en el interior de la cueva; B. Maza ofítica con huellas de impacto en sus extremos encontrada en un depósito exterior. 
siblemente ofrendas. Los perros identificados no fueron consumidos (Benítez de Lugo et al. e. p. 2015) (1).

La prominencia de Castillejo del Bonete había llamado la atención de los lugareños desde tiempos inmemoriales. Los topónimos "castillejo" ("montoncito" o "fortificación en un alto") y "bonete" (del latín abonnis: "gorro" puesto sobre una cabeza) atestiguan su identificación con algo añadido a la superficie del terreno. Antes de las intervenciones arqueológicas el yacimiento realmente se asemejaba a una potente estructura tumular sobrepuesta al terreno característico del
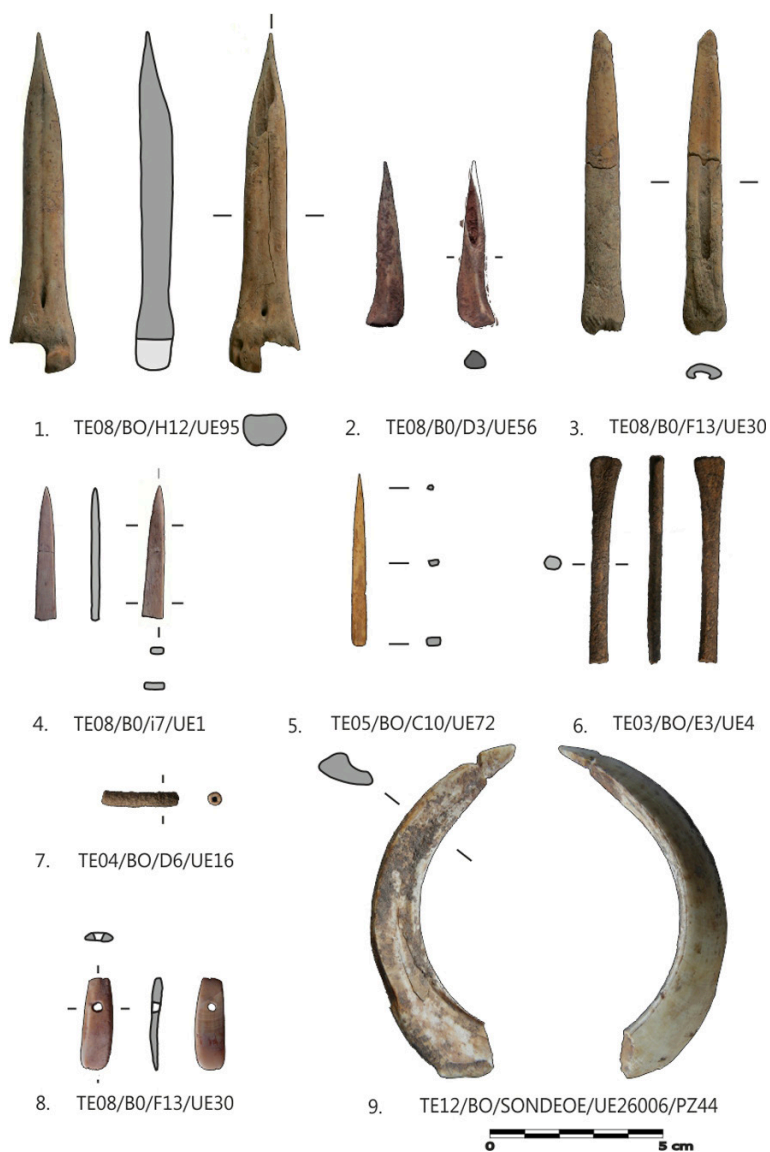

Fig. 9. Castillejo de Bonete (Terrinches, Ciudad Real). Muestra de industria ósea.

(1) La relevancia de los materiales y construcciones encontradas en Castillejo del Bonete ha supuesto que en abril de 2014 la Dirección General de Cultura de la Junta de Comunidades de Castilla-La Mancha abriera el expediente para su declaración como Bien de Interés cultural, con la categoría de Zona Arqueológica (Diario Oficial de Castilla-La Mancha 2014). entorno. Su aspecto no difería mucho del de una motilla de tamaño medio, aunque no se encuentra en llano ni asociada a vegas, lagunas o cauce alguno. Junto a ese túmulo había otros "majanos" (montones de piedras) menores. Según Marcelino, vecino de Terrinches, "el lugar estaba sembrado de ellos".

Las investigaciones arqueológicas desarrolladas en el sitio durante 2012 y 2013 han permitido avanzar una interpretación, según la cual, los niveles de uso detectados no son de hábitat y las arquitecturas registradas se erigieron más en clave monumental que defensiva (Benítez de Lugo et al. e. p. 2014). Los potentes muros curvos identificados (Fig. 6) no son los restos de una torre sino una barrera física creada para evitar que las piedras acumuladas en torno a la sima penetraran en su interior. Los amontonamientos de piedra tienen más de $2 \mathrm{~m}$ de altura y forman un túmulo al que se adosaron recintos funerarios, como el que contenía la Tumba 4, doble (Fig. 7). Junto al húmero derecho del Individuo 1 fueron encontrados dos botones de marfil con perforación en $\mathrm{V}$ de probable procedencia argárica, vinculados a una pieza de tela o piel que no se ha conservado. Los análisis realizados han identificado, en los agujeros del botón, restos de la fibra trenzada de esparto, utilizada para coserlo a la tela. Esta persona se alimentó con proteína marina (Salazar-García et al. 2013).

Alrededor de la entrada a la sima sobre la que se construyó el túmulo y en recintos específicos del mismo, se excavaron hoyos de diverso tipo de donde proceden parte de las cerámicas, restos de fauna y metales mencionados. Estos depósitos se rellenaron y taparon con piedras.

Los constructores del monumento resolvieron el acceso a la cueva mediante un pasillo descendente de aproximadamente $1,20 \mathrm{~m}$ de anchura, flanqueado por una potente muralla de mampostería situada al Este, que conserva hasta diez hiladas de altura (Fig. 10). En la entrada a la sima se identifican una serie de lajas de roca caliza dispuestas de modo descendente con superficie plana que, a buen seguro, funcionaron como escalones. Es posible identificar con claridad, al menos, cuatro que apoyan sobre una roca madre caliza rebajada. El pasillo se prolonga en galerías y espacios acondicionados artificialmente. En el primer vestíbulo de $5,20 \times 2 \mathrm{~m}$ de planta y 1,70 $\mathrm{m}$ de altura puede apreciarse la construcción, a base de mampuestos de caliza, de un apoyo de la 
bóveda pétrea de roca carbonatada (Fig. 11A, B). Aunque fisurada, se halla bien consolidada sin apreciarse derrumbes recientes, pudiendo considerarse que la estructura interior de la cueva no ha variado sustancialmente desde su ocupación. La altura con respecto al nivel del suelo original debía ser mucho mayor, ya que los sedimentos procedentes del exterior que colmatan la sima ocultan por el momento el contacto con el suelo de la Edad del Bronce (Fig. 11C). De este primer vestíbulo parte una segunda galería de similar longitud a la anterior, que termina en otro vestíbulo de unos 4,20 x $3 \mathrm{~m}$ con 1,7 m de altura libre desde el nivel de escombros (Fig. 11D). En su extremo norte se abre en rampa descendente otra galería o sima inaccesible. En la actualidad el fondo de la cueva está cegado por la colmatación. La cueva se cerró durante la Prehistoria Reciente, para no ser reabierta hasta la actualidad.

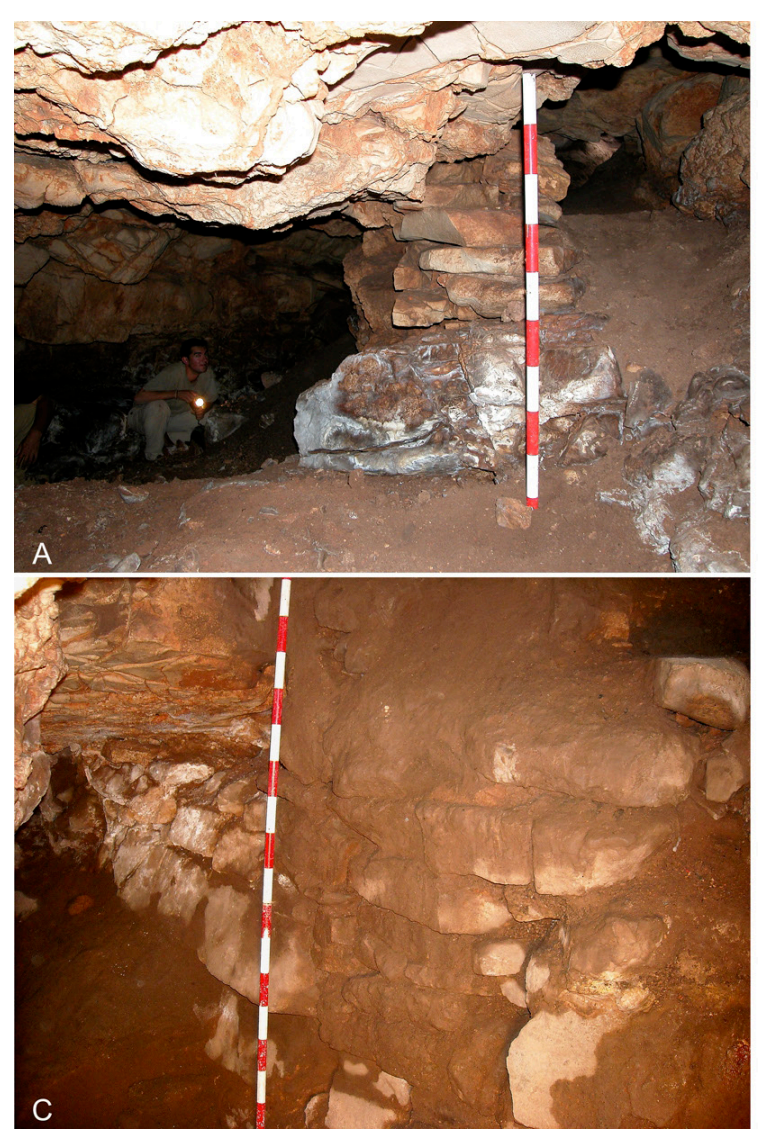

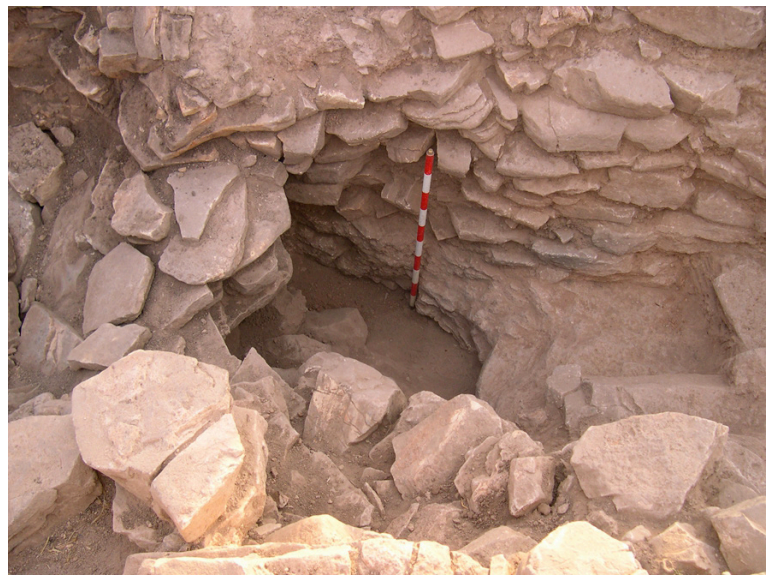

Fig. 10. Castillejo del Bonete (Terrinches, Ciudad Real): muros edificados para acceder al interior de la cueva natural. La altura conservada del muro en ese punto es $1,72 \mathrm{~m}$, pero desde la grieta que da acceso a la cueva hasta la parte más elevada del túmulo llega a los $2,36 \mathrm{~m}$. Esta sería la altura mínima constatable del túmulo.

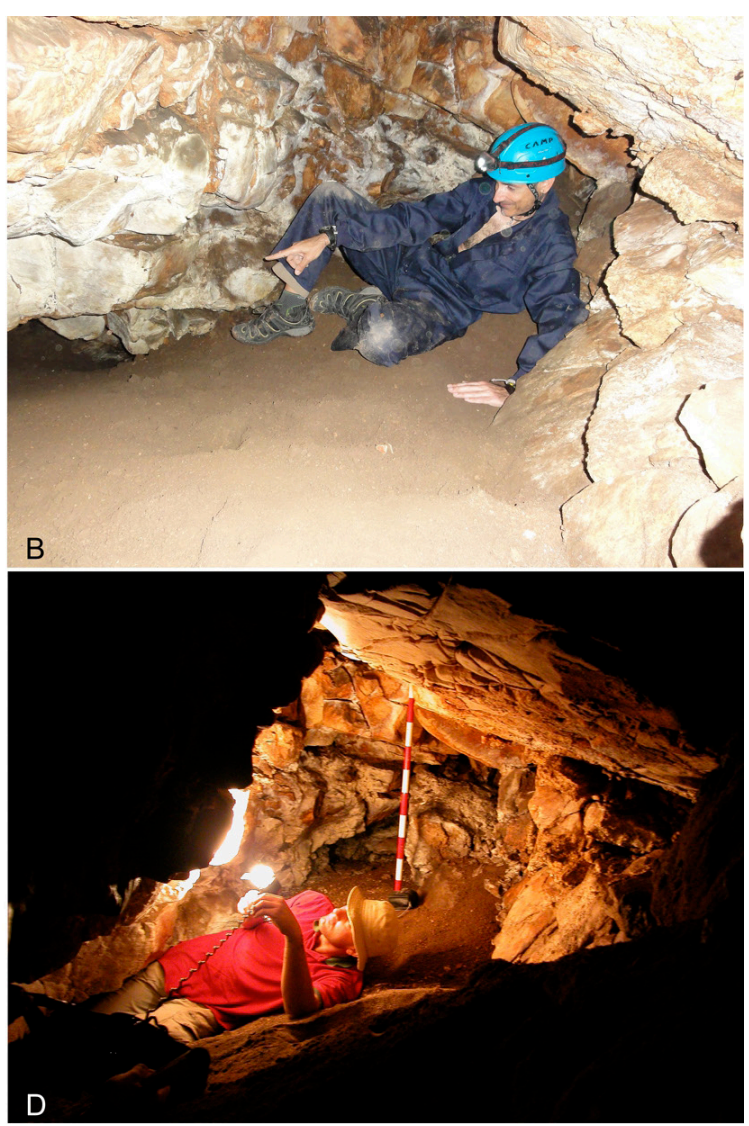

Fig. 11. Sima natural de Castillejo de Bonete (Terrinches, Ciudad Real). Primer vestíbulo: A. Machón artificial de lajas calizas (EMT); B. Aspecto de la formación natural caliza, del suelo, formado por depósitos externos, y de la colmatación de una de las galerías inferiores (JLG); C. Muro de mampostería careada para acondicionar el interior; D. Morfología de las calizas y el suelo en el segundo vestíbulo (HJAG). 
El túmulo edificado sobre la sima dispone de dos grandes corredores de entrada con planta en forma de embudo, orientados al Este y al Oeste. Sobre una de las paredes del occidental se colocó un recipiente cerámico sujeto con piedras. Un tercer corredor de más de $20 \mathrm{~m}$ de longitud, construido con lajas de caliza levantadas en vertical desde la roca madre también caliza, conecta este túmulo principal (Fig. 6B, C) con otro de menor tamaño, pendiente aún de excavación arqueológica. Un cuarto corredor similar al anterior parte del túmulo principal hacia el Norte. En la actualidad, se han excavado $8 \mathrm{~m}$ del mismo. Parece dirigirse hacia un tercer túmulo, aún no descubierto.

Al inicio de la investigación las hipótesis de trabajo sobre el uso que este grupo prehistórico dio a Castillejo del Bonete tenían en cuenta bien la sima (acceso al acuífero del Campo de Montiel, beneficio de algún tipo de metal), bien las arquitecturas y los enterramientos documentados. Ahora sabemos que el sitio fue algo más que un monumento funerario con fuerte carga simbólica. Hasta finales de 2012 habían sido recuperados 6 depósitos, algunos con restos humanos en posición secundaria. Son pocos para un uso que se presume dilatado durante la Prehistoria Reciente. El mejor conservado es la citada Tumba 4, situada al exterior del túmulo principal (Fig. 7). Es probable que esta tumba corresponda a uno de los últimos enterramientos de Castillejo del Bonete..

La datación disponible de la Tumba 4 procede del colágeno del fémur del Individuo 2, probablemente el primero enterrado, corresponde al último tercio del III milenio cal. AC. Este enterramiento doble fue documentado en un recinto con puerta de acceso adosado al túmulo principal. La datación, según los estudios realizados en Motilla del Azuer, se sitúa a caballo entre el Bronce Antiguo y Pleno (Nájera et al. 2010: 77). Se trataría de un enterramiento prácticamente coetáneo (unos noventa años más reciente) al también enterramiento doble de la pequeña cámara circular de piedras (cercana a $1 \mathrm{~m}$ de diámetro), adosada al sureste del Túmulo de El Castillejo (Huecas, Toledo). Se le considera calcolítico. En su ajuar estaba presente el campaniforme y proporcionó una fecha $3810 \pm 70 \mathrm{BP}(2466-2040$ cal. BC a $2 \sigma ; 2400-2140$ cal. BC a $1 \sigma$ ) (Bueno et al. 2002: 70; Bueno et al. 2007-2008: 777, 2009).

En Castillejo del Bonete se ha fechado también una falange humana, asociada a variscitas
(Fig. 8), procedente del interior de la cueva. Podría ser ligeramente anterior, correspondiendo al tercer cuarto del III milenio cal. AC. (Fig. $12 \mathrm{~A}$ y B, Tab. 1).

Se presentan a continuación los resultados de la investigación que lleva a descartar el uso de las galerías de la sima de Castillejo del Bonete como acceso al acuífero del Campo de Montiel o para la explotación minera.

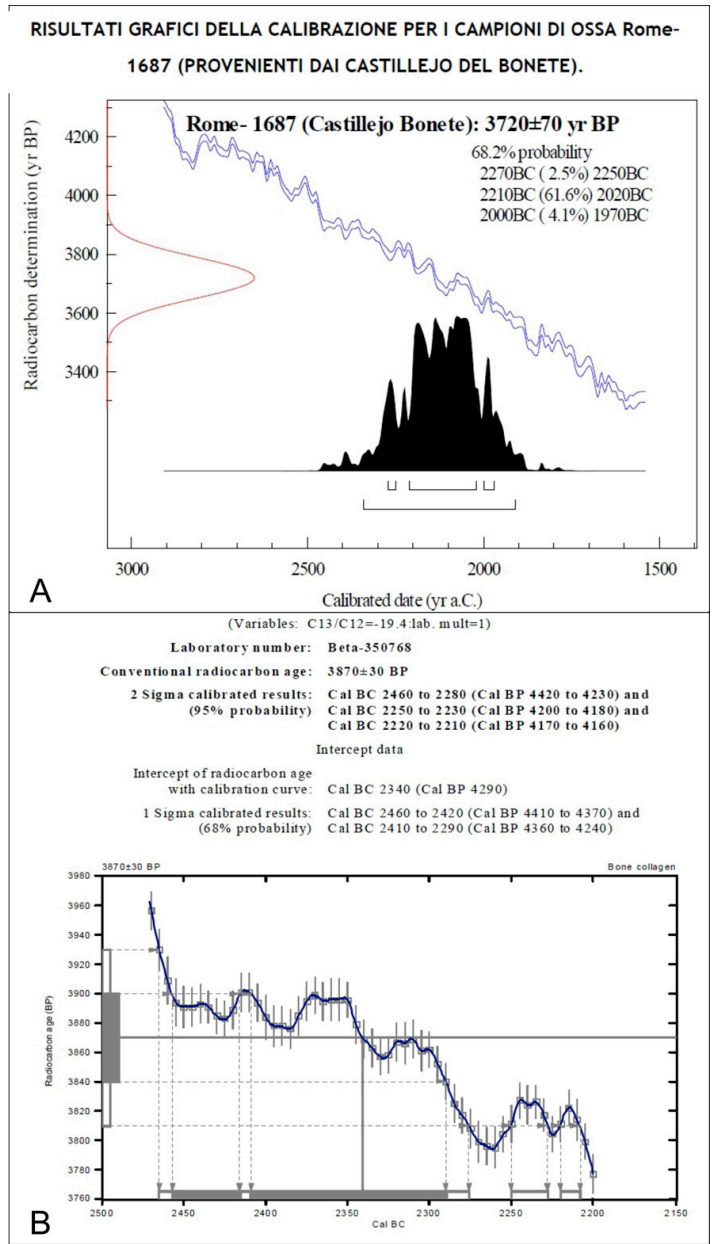

Fig. 12. Gráficas de los análisis radiocarbónicos sobre colágeno del fémur del Individuo 2 de la Tumba 4 (Fig. 6A*, aneja al túmulo principal) (A: Rome 1687) y de una falange de varón adulto, asociada al conjunto de colgantes de variscita encontrada en la cueva cubierta por el túmulo principal de Castillejo del Bonete (B: Beta 350768). 


\begin{tabular}{|c|c|c|c|c|}
\hline Castillejo del Bonete & Ref. Lab & Edad ${ }^{14} \mathrm{C}$ BP & cal BC (1б) & 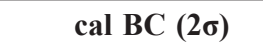 \\
\hline Tumba 4 & Rome-1687 & $3720 \pm 70{ }^{14} \mathrm{C} B P$ & 2271-1984 calBC & $2340-1920$ calBC \\
\hline Interior cueva & Beta-350768 & $3870 \pm 30{ }^{14} \mathrm{C} \mathrm{BP}$ & $2456-2293$ calBC & 2466-2211 calBC \\
\hline
\end{tabular}

Tab. 1. Dataciones de restos óseos humanos de Castillejo del Bonete (Terrinches, Ciudad Real). Las dataciones han sido calibradas con el programa OxCal 4.2beta. (Bronk Ramsey 2009; Reimer et al. 2009).

\section{INVESTIGACIÓN GEOLÓGICA E HIDROGEOLÓGICA EN LA MANCHA}

\subsection{Ubicación y análisis hidrogeológico de las motillas}

La distribución espacial de las motillas muestra dos rasgos hidrogeológicos comunes (Fig. 13) (Mejías et al. e. p. 2014). El primero es que, aunque no siempre están asociadas a cauces fluviales en sentido estricto, suelen establecerse sobre depósitos cuaternarios aluviales, fácilmente excavables, en conexión hidráulica con la red de drenaje principal. Ello eleva la probabilidad de interceptar el agua subterránea conectada a los ríos o alcanzar el nivel freático regional.. Las motillas de Albuera y El Acequión se sitúan en entornos con el agua subterránea aflorante o subaflorante, una en las Tablas de Daimiel y la otra en la Laguna de El Acequión, desecada artificialmente en el siglo XVIII. La motilla de Perales, en realidad, la única alejada de cauces o afloramientos de agua, se asienta sobre depósitos cuaternarios de tipo glacis, procedentes de la altiplanicie de Campo de Montiel, que tapizan materiales terciarios carbonatados, donde resulta relativamente sencillo alcanzar el agua subterránea.

El segundo rasgo hidrogeológico compartido es la localización del nivel freático a menos de $20 \mathrm{~m}$ de profundidad, en condiciones no antropizadas, lo que facilita el acceso al agua subterránea. Este tipo de captaciones, como los pozos actuales situados en las llanuras aluviales, se beneficia de la capacidad de regulación de los acuíferos y de la disponibilidad espacial del agua incluso cuando los cauces principales se secan. Las ventajas de esa regulación aparecen cuando, al estar muy distanciados en el tiempo los eventos de recarga (por lluvia principalmente), los gradientes hidráulicos y la velocidad del flujo subterráneo disminuyen. El nivel freático permite obtener recursos en verano o en periodos secos, procedentes de los episodios de lluvia del otoño o el invierno anteriores. En situaciones de acuíferos muy extensos o con grandes espesores como es el caso de La Mancha occidental, esta inercia puede ser de años, decenas de años o incluso superior. Además, el agua subterránea se puede obtener donde se precise, sin necesidad de conducciones desde los cauces principales. De este modo se pueden primar los condicionantes defensivos, o de cualquier otro tipo, sobre la proximidad a los cauces al plantear los asentamientos de población o las actividades económicas.

La figura 14 muestra que el condicionante geológico de las motillas situadas en las unidades hidrogeológicas 04.04, Mancha Occidental, y 04.06, Campo de Montiel, son los depósitos detríticos aluviales de los ríos principales, que se encajan tanto en los sedimentos terciarios de la UH 04.04 como en los materiales carbonatados jurásicos de la UH 04.06. Es decir, desde un punto de vista geológico, todo parece indicar que para construir una motilla las comunidades prehistóricas eligieron terrenos y materiales de excavación manejable y con facilidad de acceso al agua subterránea.

\subsection{Castillejo del Bonete como posible captación de aguas subterráneas}

La ubicación del yacimiento de Castillejo de Bonete, desde el punto de vista hidrogeológico, se diferencia con claridad de la de las motillas. Se asienta sobre materiales carbonatados jurásicos (dolomías del Lías) de la unidad hidrogeológica 05.65, Campo de Montiel, de la cuenca del Guadalquivir (compartida con la unidad hidrogeológica 04.06 también denominada Campo de Montiel, en la cuenca del Guadiana). Las dolomías son duras, difíciles de excavar y, presumiblemente, el nivel freático se encuentra a mayor profundidad que en los emplazamientos de las motillas. Sin embargo, la cavidad natural allí existente hizo pensar en su posible aprovecha- 


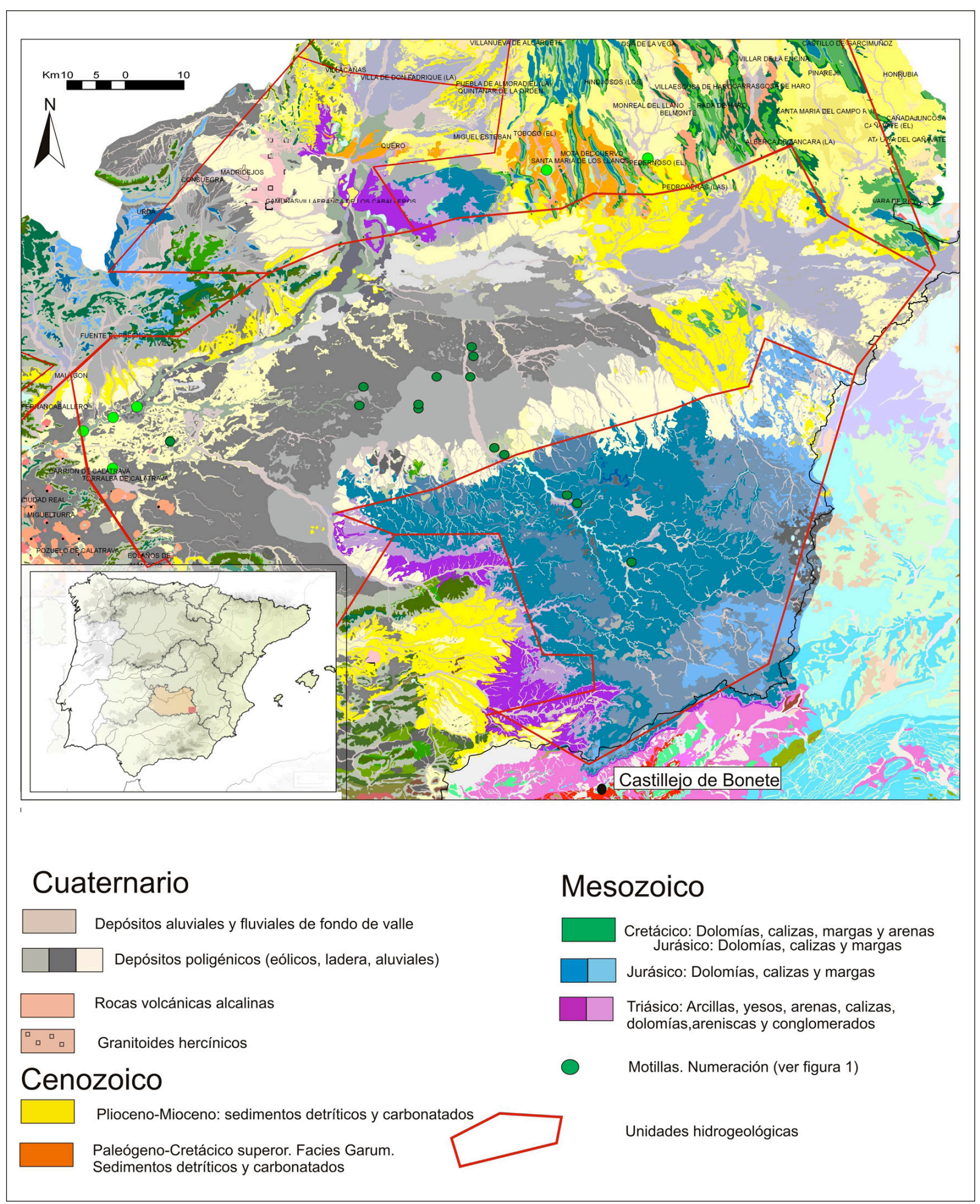

Fig. 13. Mapa geológico de la zona de distribución de las motillas. Análisis de su distribución hidrogeológica. http://mapas.igme.es/gis/services/Cartografia_Tematica/IGME_Litoestratigráfico_200/MapServer/WMSServer y elaboración propia. 

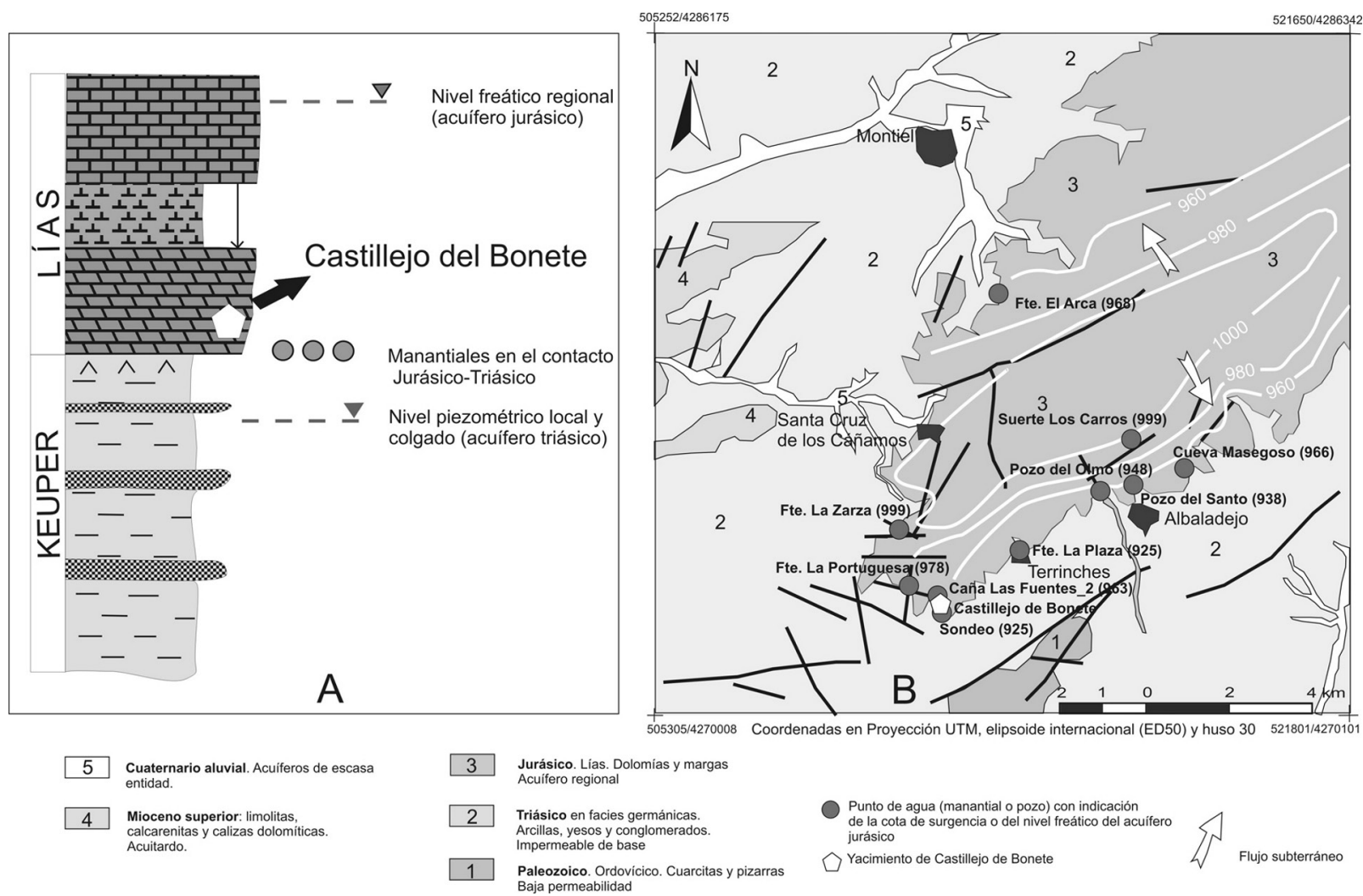

Fig. 14. A. Esquema de la posición estratigráfica de Castillejo del Bonete y de los manantiales del entorno. B. Mapa hidrogeológico, esquema piezométrico basado en dichos manantiales y posición estratigráfica de los mismos: Caña Las Fuentes, La Portuguesa, La Zarza, El Arca, La Plaza, Masegoso, Olmo y El Santo. Modificado de Mapa Geológico de España E. 1:50.000 (MAGNA). Hoja 839. Torre de Juan Abad y 840 Bienservida. IGME.

miento y acondicionamiento para acceder al agua subterránea. Para comprender el funcionamiento hidrogeológico del entorno del emplazamiento y la posibilidad de captación de agua con medios tecnológicos prehistóricos se planteó un estudio hidrogeológico local.

Primero se inventariaron los puntos de agua caracterizando la hidrogeología de los materiales aflorantes. Tras seleccionar los puntos más representativos se procedió a su nivelación topográfica y a la toma de datos de caudal en los manantiales, de profundidad del nivel freático en pozos, de profundidad del nivel piezométrico en sondeos y los parámetros físico-químicos (conductividad eléctrica, $\mathrm{pH}$ y temperatura).

Como resultado, se identificaron dos acuíferos estratigráficamente superpuestos. El superior, jurásico, está constituido por calizas, con recursos de buena calidad química, con conductividades eléctricas entorno a los $550 \mu \mathrm{S} / \mathrm{cm}$. Representa el acuífero aprovechado en toda la región y en el se desarrolla la cavidad de Castillejo de Bonete. Los materiales del acuífero inferior, triásico en facies Keuper, afloran inmediatamente al sur de los resaltes calizos jurásicos que constituyen el acuífero superior. Aunque en conjunto la litología de las facies Keuper son arcillas de baja permeabilidad con yesos, existen intercalaciones arenosas con espesores que rara vez superan $1,5 \mathrm{~m}$, que dan lugar a pequeños niveles productivos y manantiales. Sus recursos son escasamente aprovechados debido a su mala calidad natural, con conductividades eléctricas próximas a los 2000 $\mu \mathrm{S} / \mathrm{cm}$, debido posiblemente a la alta concentración de sulfatos por influencia de los niveles yesíferos. Por lo tanto, el acuífero objeto de estudio corresponde al Jurásico, asimilando el Triásico al impermeable de base cuyo principal papel es permitir las surgencias del acuífero superior jurásico (manantiales). 
Una serie de manantiales se originan entorno al yacimiento en las cabeceras de los arroyos y drenan los materiales jurásicos, en su contacto basal con las arcillas triásicas. La figura 14A muestra la posición estratigráfica de los manantiales y de Castillejo del Bonete. Se identificaron un total de 9 surgencias (Fig. 15) con caudales muy reducidos (menores de $0,5 \mathrm{~L} / \mathrm{s}$, excepto el pozo del Olmo, con 2,5 L/s en octubre de 2012), pero mantenidos en el tiempo, ya que funcionaban tanto en junio como en octubre de 2012. Ello indica que las descargas se sostienen en el periodo de estiaje del año pluviométrico 2011-2012, que se clasifica en las estaciones termopluviométricas del entorno como de tipo seco, si bien los dos años hidrológicos anteriores fueron de tipo húmedo (elaboración propia a partir de datos de la Agencia Estatal de Meteorología española, AEMET).

A partir de las cotas niveladas de las surgencias se ha establecido un esquema piezométrico. En este sector del acuífero jurásico se ha identificado una divisoria de aguas subterráneas, de dirección NE-SO, situada inmediatamente al norte del Castillejo del Bonete. Al N de esta divisoria, el flujo subterráneo se dirige hacia el NO, es decir, hacia la cuenca del Guadiana y al S de la misma discurre hacia el SE, es decir, hacia la cuenca del Guadalquivir. Esta divisoria coincide aproximadamente con la de las aguas superficiales. De este modo, todos los manantiales identificados en el frente jurásico entre Castillejo del Bonete y Albadalejo representan la descarga natural de este pequeño sector del acuífero jurásico de Campo de Montiel (con una anchura de unos $3 \mathrm{~km}$ ), que drena hacia la cuenca del Guadalquivir. Estos puntos de drenaje se originan en las cabeceras de distintos arroyos tributarios del río Guadalmena, que vierte sus aguas hacia el Guadalquivir.

En el entorno inmediato de Castillejo del Bonete, la cota del agua subterránea se puede establecer a partir de las surgencias de la fuente de La Portuguesa, situada $1 \mathrm{~km}$ al NO del yacimiento, a cota 978 m s.n.m., el manantial de la Cañada de las Fuentes, situada a $250 \mathrm{~m}$ al NNO de Castillejo del Bonete, a cota 963 m s.n.m., y, sobre todo, en un sondeo próximo situado a unos $40 \mathrm{~m}$ al sur de la excavación arqueológica. En este último punto, que capta el acuífero jurásico, la profundidad promedio del agua es de $46 \mathrm{~m}$ a cota 923 m s.n.m. (Fig. 14B). Estos datos establecen dos aspectos muy significativos para evaluar el acceso al acuífero a través de las galerías de la cueva de Castillejo del Bonete. A menos de $1000 \mathrm{~m}$, en condiciones pluviométricas similares a las actuales, la población contaría con dos surgencias (Fuente de la Portuguesa y $\mathrm{Ca}$ ñada de las Fuentes) activas todo el año. Ello haría innecesario acceder al agua a través de una cavidad, lo que supondría unas dificultades considerables para su transporte a la superficie. En condiciones más secas que las actuales dejaría de manar primero la fuente de La Portuguesa que se encuentra a mayor cota- $y$, posteriormente, el manantial de Cañada de las Fuentes. Si la cavidad de Castillejo del Bonete tuviera desarrollo vertical -lo que no se sabe por el momentoy tomando como referencia el sondeo anteriormente citado, el agua se encontraría a $46 \mathrm{~m}$ de profundidad y a una cota menor que las surgencias naturales. Por ello, en situaciones pluviométricas desfavorables, y cuando los manantiales hipotéticamente dejasen de manar, en el fondo de la cavidad podría seguir existiendo agua a esa profundidad. Sin embargo, el descenso a ella y el ascenso cargándola se presume complicado, ya que debería salvarse una cota vertical equivalente aproximadamente a un edificio de 15 plantas.

En conclusión, a pesar de que durante la Prehistoria Reciente pudiese circular agua subterránea por el fondo de la cavidad, el acceso a ella y, sobre todo, su elevación en cantidades aprovechables para el abastecimiento hídrico de una comunidad con cabaña ganadera, exigiría acciones muy complejas y altamente improbables con tecnología prehistórica. Esta consideración es independiente del eventual funcionamiento de los manantiales del entorno durante la Prehistoria Reciente.

En la actualidad la incipiente excavación arqueológica en las galerías de Castillejo del Bonete no permite precisar la profundidad de la sima, ni si desciende hasta el nivel del acuífero. Sin embargo, sí resulta posible concluir que el acceso al agua a través de la sima de Castillejo del Bonete, de haberse producido, no tuvo una finalidad subsistencial o de abastecimiento. 


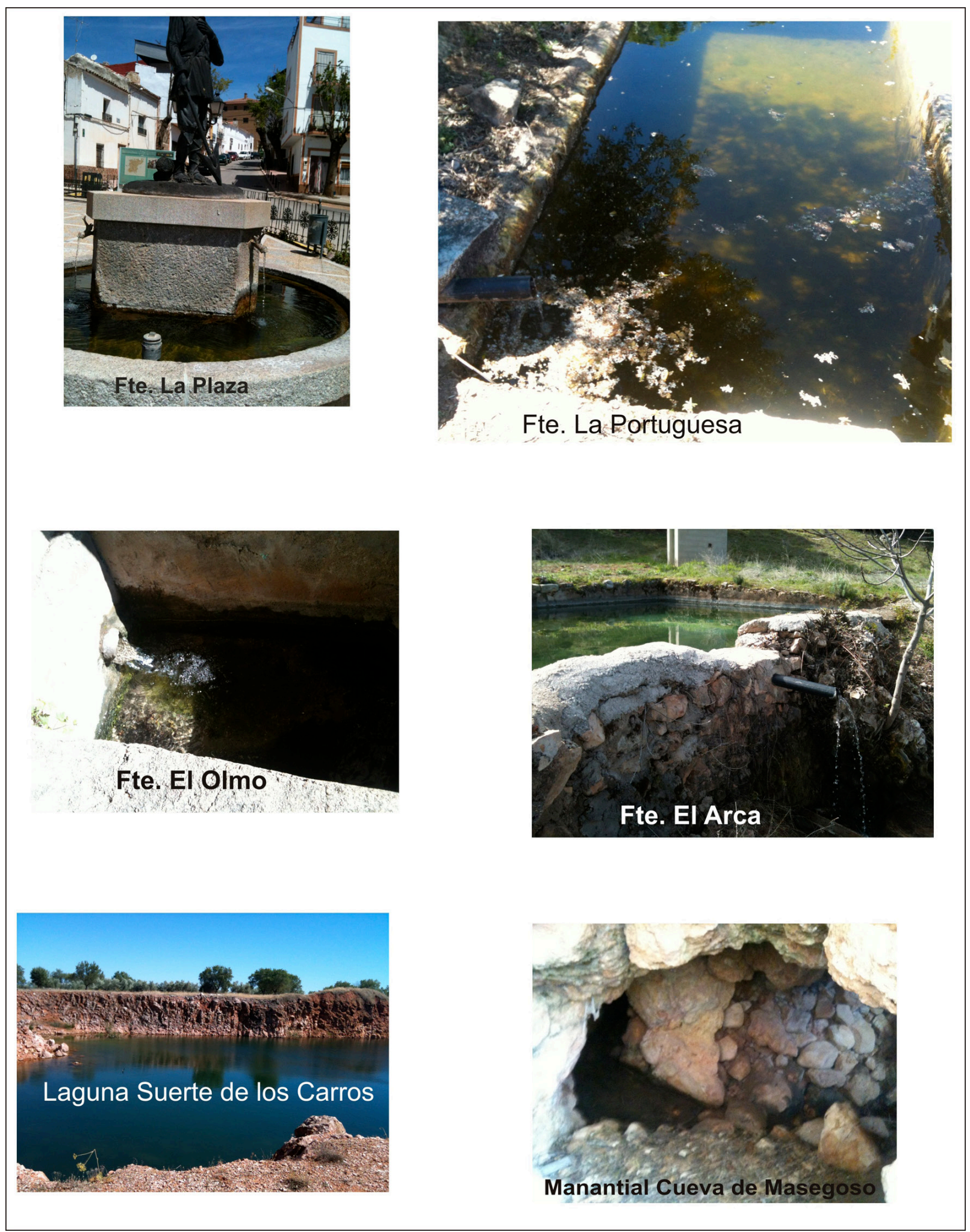

Fig. 15. Manantiales de agua próximos a Castillejo del Bonete (Terrinches, Ciudad Real). Se localizan en la figura 14. 


\subsection{Castillejo del Bonete como posible mina}

La hipótesis inicial del eventual aprovechamiento minero de las galerías subterráneas de Castillejo del Bonete consideraba la asociación entre este tipo de explotaciones y asentamientos adscritos a la Prehistoria Reciente en Castellar de Santiago (Morra de El Castellón) y Santa Cruz de Mudela (Noria Olaya) (Benítez de Lugo y Menchén 2010), o la existencia de minas adscritas a esta época en la vecina provincia de Toledo (Montero et al. 1999). En Castillejo del Bonete ha sido recuperada una maza elaborada sobre piedra ofítica, de $122 \mathrm{~mm}$ de longitud y con huellas de impacto en sus extremos (Fig. 8B) en uno de los depósitos exteriores, pendiente de una excavación completa. Pudo ser utilizada en trabajos de cantería o, quizá mineros, en el interior de la cueva. Castillejo del Bonete está a unos $100 \mathrm{~km}$ al norte de Peñalosa (Baños de la Encina, Jaén), poblado argárico especializado en metalurgia y emplazado en la vertiente opuesta de Sierra Morena (Contreras 2000).

A priori, el contexto geológico de Castillejo del Bonete, ubicado en dolomías jurásicas, hace difícil la presencia de yacimientos mineros metálicos. De hecho no constan indicios mineros en esta formación y región. Tras analizar la cartografía metalogenética del Instituto Geológico y Minero de España (IGME, hojas a escala 1:200.000, n. ${ }^{\circ} 70$ Linares y n. ${ }^{\circ} 71$ Villacarrillo) se observa que los yacimientos de Castellar de Santiago $(40 \mathrm{~km}$ al oeste de Castillejo del Bonete) y de Santa Cruz de Mudela $(53 \mathrm{~km}$ también al oeste) están en un distrito minero de entidad mediana, en el que la asociación mineral son sulfuros de antimonio, arsénico y bismuto de tipo filoniano, sin que exista cobre como sustancia susceptible de explotación. La formación encajante son esquistos, cuarcitas y conglomerados devónicos (Paleozoico), y el proceso genético es epitermal, relacionado con la parte culminante de los sistemas ígneos tardi-variscos. No tienen, por tanto, similitud alguna con las formaciones de Castillejo del Bonete y los procesos metalogenéticos del distrito minero en el que se encuentran son absolutamente anacrónicos con las formaciones jurásicas donde se emplaza el yacimiento. Tampoco en Castillejo del Bonete, ni en la sala subterránea de acceso, ni en el tramo descubierto de las galerías se aprecian los indicios de sustancias metálicas aprovechables o de activi- dad minera, habituales en los yacimientos mineros.

El conjunto de estos motivos permite también descartar el uso de la cueva de Castillejo del Bonete para la captación de mineral. Su utilización ha de explicarse bajo otros parámetros.

\section{CONCLUSIONES}

La investigación interdisciplinar presentada ha analizado la hidrogeología de los manantiales del acuífero de Campo de Montiel y del interior de la sima de Castillejo del Bonete tanto para la caracterización arqueológica de este yacimiento como para estudiar la distribución espacial de las motillas, asentamientos típicos de la cultura de la Edad del Bronce de La Mancha.

Los resultados del trabajo permiten reforzar la relación entre el sustrato hidrogeológico y el emplazamiento de las motillas. Para su construcción las gentes de la citada cultura eligieron terrenos excavables sin gran esfuerzo con tecnología prehistórica y con fácil acceso al agua subterránea. Esto ocurre en la Mancha Occidental pero no en el Campo de Montiel. Será preciso esperar al desarrollo de futuras investigaciones arqueológicas en otras motillas diferentes a la del Azuer (Figs. 2, 3B y 4) para comprobar si se generaliza la presencia de pozos, como los datos disponibles parecen apuntar. En definitiva, la ausencia de motillas en el Campo de Montiel, fuera del ámbito de la ribera del río Guadiana, puede ser explicada en clave hidrogeológica y tecnológica, más que cultural. La construcción de estos monumentos hubo de realizarse en un prolongado momento de sequía que, desde luego, excede el estío anual durante el cual las aguas corrientes superficiales desaparecieron de esta comarca manchega (Fig. 16). Aquella sequía puede estar relacionada con el Evento Climático 4,2 ka BP, que se prolongó entre el 4000 y el $3700 \mathrm{BP}$ (ca. 2450-1950 cal. a.C.), dentro del período Subboreal; es decir, en la transición del Calcolítico a la Edad del Bronce en la zona. Es uno de los eventos climáticos holocenos de aridez más extrema, registrado a escala mundial. Se relaciona con una oscilación de la órbita terrestre que modificó la radiación solar recibida por la Tierra (Gibbons 1993; Weiss et al. 1993; Wilkinson 1997; Menotti 1999; Carrión et al. 2001; Julià et al. 2001; Fábregas et al. 2003; López Sáez y Blanco 2003;

Trab. prehist., 71, N. ${ }^{\circ}$ 1, enero-junio 2014, pp. 76-94, ISSN: 0082-5638

doi: $10.3989 /$ tp. 2014.12125 
Francisco et al. 2006; Fagan 2007: 253). Es posible que esa crisis ambiental, hasta ahora poco caracterizada en La Mancha, tuviera una relación directa con el origen y la desaparición de las motillas (Benítez de Lugo 2010: 52, 2011a: 147, 2011b: 60; Benítez de Lugo y Mejías 2014).

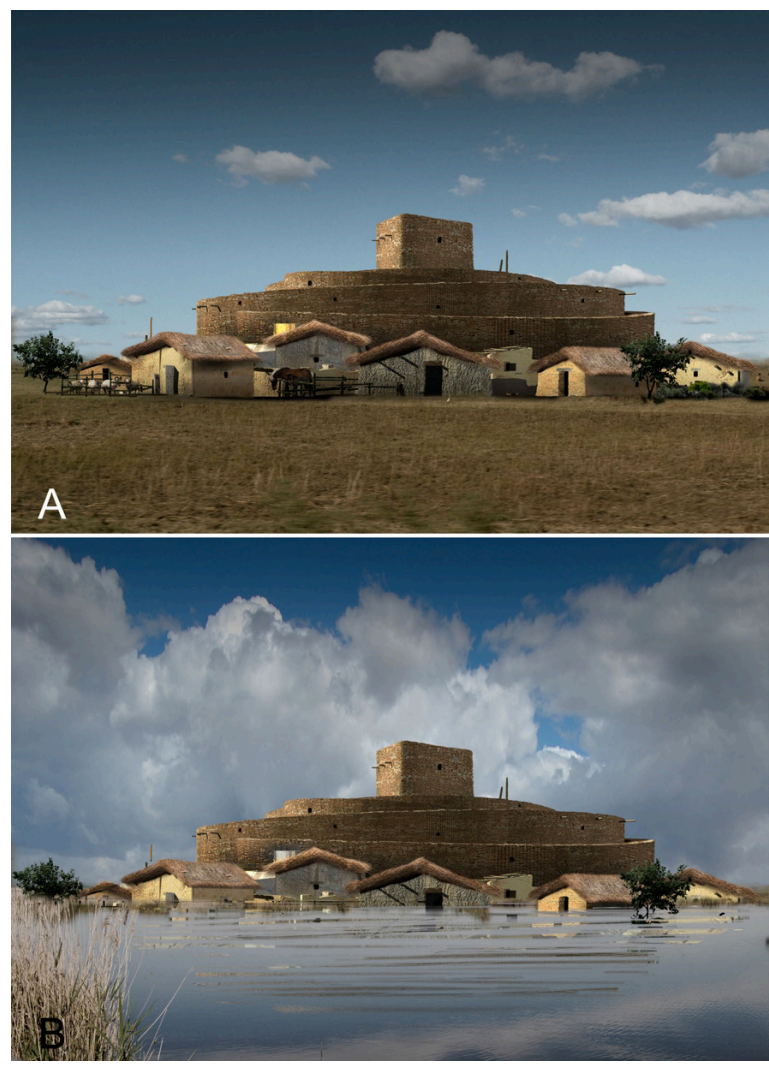

Fig. 16. Reconstrucción ideal de una motilla, una aldea agropastoril, instalada en el antiguo cauce de un río donde se ha excavado un pozo, en dos situaciones ambientales (dibujos Balawat; propiedad IGME): A. Desertización durante una fuerte y prolongada sequía que excede el estío anual; B. Inundación cuando las aguas superficiales volvieron a discurrir por el cauce.

Otra conclusión de esta investigación es que la frecuentación de la sima de Castillejo del Bonete, en el Campo de Montiel, durante la Prehistoria Reciente, no iba destinada ni a extraer agua subterránea, ni a explotar mineral (dos de las hipótesis inicialmente planteadas). La maza ofítica encontrada debió ser usada probablemente en labores locales de cantería. El acceso al nivel freático a través de las simas de Castillejo del Bonete, sin estar completamente descartado, es poco probable.
Finalmente, la continuación de los trabajos arqueológicos y la aparición en diciembre de 2012 en el interior de la cueva de restos humanos, asociados a varias decenas de cuentas de variscita (Fig. 8B) y más piezas metálicas, abona una tercera hipótesis interpretativa: su condición de monumento funerario y simbólico. Consideramos Castillejo del Bonete como una reserva arqueológica de interés para avanzar en el conocimiento de la transición entre el Calcolítico y la Edad del Bronce en el interior de la Península Ibérica. Este singular monumento fue utilizado durante la Prehistoria Reciente en un territorio tradicionalmente adscrito a la cultura de la Edad del Bronce de La Mancha. Está fechado en la primera mitad del II milenio a.n.e. pero sus orígenes están en el III milenio a.n.e., según la evidencias materiales recuperadas en el lugar. Sería una pervivencia, al sur de la Meseta y sin paralelos conocidos, de las ancestrales creencias, rituales y usos sociales que impulsaron desde tiempos neolíticos a enterrar ofrendas y a algunos difuntos bajo imponentes túmulos que monumentalizaron el paisaje en puntos estratégicos, de amplia visibilidad y vinculados a corredores naturales de paso.

\section{AGRADECIMIENTOS}

A los Dres. María Isabel Martínez Navarrete, Ignacio Montero Ruiz, Susana Consuegra Rodríguez, Pedro Díaz-del-Río Español y Marta Moreno García (IH-CCHS, CSIC, Madrid), Gonzalo Aranda Jiménez y Margarita Sánchez Romero (Universidad de Granada), Primitiva Bueno, Rodrigo de Balbín y Rosa Barroso (Universidad de Alcalá de Henares) y Antonio Gilman (California State University) su asesoramiento o apoyo público expreso a esta investigación. Algunas de sus sugerencias, así como las de los evaluadores externos de $T P$, están recogidas en este texto. Los errores u omisiones son exclusivamente de nuestra responsabilidad.

Al personal del Ayuntamiento de Terrinches y especialmente a su Alcalde, D. Nicasio Peláez Peláez, sin cuyo apoyo institucional, económico y logístico la investigación sobre Castillejo del Bonete no habría sido posible.

Al Servicio de Protección de la Naturaleza (SEPRONA) de la Guardia Civil, que por iniciativa propia incorporó a Castillejo del Bonete en sus rutas de inspección. 
Esta publicación ha sido autorizada por la Dirección General de Cultura de la Junta de Comunidades de Castilla-La Mancha (Exp. Cult. 121478).

\section{BIBLIOGRAFÍA}

Aranda, G.; Fernández, S.; Haro, M.; Molina, F.; Nájera, T. y Sánchez-Romero, M. 2008: "Water control and cereal management on the Broze Age Iberian Peninsula: la Motilla del Azuer". Oxford Journal of Archaeoloy 27 (3): 241-259.

Benítez de Lugo, L. 2010: Las motillas y el Bronce de La Mancha. Anthropos. Valdepeñas (Ciudad Real).

Benítez de Lugo, L. 2011a: "Las motillas del Bronce de La Mancha: treinta años de investigación arqueológica”. En P. Bueno, A. Gilman, C. Martin y J. Sánchez-Palencia (eds.): Arqueología, sociedad, territorio y paisaje. Estudios sobre Prehistoria Reciente, Protohistoria y transición al mundo romano en homenaje a M. ${ }^{a}$ Dolores Fernández Posse. Bibliotheca Praehistorica Hispana XXVIII, Consejo Superior de Investigaciones Científicas. Madrid: 141-162.

Benítez de Lugo, L. 2011b: “Orígenes, desarrollo y ocaso de la cultura del Bronce de La Mancha. Nuevas aportaciones a los procesos de transformación y cambio en el Alto Guadiana durante la Prehistoria Reciente". QPAC-Quaderns de Prehistòria i Arqueologia de Castelló 29: 47-75.

Benítez de Lugo, L.; Álvarez García, H. J.; Fernández Martín, S.; Mata Trujillo, E.; Menchén Herreros, G.; Montero Ruiz, I.; Moraleda Sierra, J.; Morgado Rodríguez, A.; Palomares Zumajo, N.; Benito Sánchez, M.; Odriozola Lloret, C.; Ruiz-Alonso, M. y Salazar-García, D. C. (en prensa): "Castillejo del Bonete (Terrinches, Ciudad Real): complejo tumular prehistórico en el Alto Guadalquivir". Menga 5, 2014.

Benítez de Lugo, L.; Álvarez García, H. J.; Fernández Montoro, J. L.; Mata Trujillo, E.; Moraleda Sierra, J.; Sánchez Sánchez, J. y Rodríguez Morales, J. 2012: "Estudio arqueológico en la Vía de los Vasos de Vicarello A Gades Romam, entre las estaciones de Mariana y Mentesa (Puebla del Príncipe, Villanueva de La Fuente, Ciudad Real". Archivo Español de Arqueología 85: 101-108.

Benítez de Lugo, L.; Álvarez García, H. J.; Palomares Zumajo, Mata Trujillo, E. y Moraleda, J. (en prensa): "Investigación de un complejo monumental prehistórico en el borde meridional de la Meseta: Castillejo del Bonete (Terrinches, Ciudad Real). Una década de intervenciones arqueológicas (20032012)". Arse 48, 2014.
Benítez de Lugo, L. y Mejías M. 2014: “Los primeros poblados prehistóricos en el entorno de Daimiel. Las motillas de la Mancha". En M. Mejías (ed.): Las Tablas y los Ojos del Guadiana: agua, paisaje $y$ gente. Instituto Geológico Minero de EspañaOrganismo Autónomo de Parques Nacionales. Madrid: 65-104.

Benítez de Lugo, L. y Menchén, G. 2010: “La Noria Olaya (Santa Cruz de Mudela, Ciudad Real). Qanat islámico y yacimiento de la Edad del Bronce". En A. Madrigal y M. Perlines (eds.): Actas de las II Jornadas de Arqueología de Castilla-La Mancha (Toledo 2006) 2. Toledo. Edición en CD sin paginar.

Benítez de Lugo, L.; Palomares Zumajo, N.; Fernández Martín, S.; Mata Trujillo, E.; Menchén Herreros, G.; Montero Ruiz, I.; Moraleda Sierra, J.; Morgado Rodríguez, A.; Álvarez García, H. J.; Benito Sánchez, M.; Odriozola Lloret, C.; Ruiz-Alonso, M. y Salazar-García, D. C. (en prensa): "Materiales arqueológicos de Castillejo del Bonete (Terrinches, Ciudad Real): estudio analítico y contexto cultural". Menga 6, 2015.

Bronk Ramsey, C. 2009: "Bayesian analysis of radiocarbon dates". Radiocarbon 51 (1): 337-360.

Bueno, P. 1990: "Megalitos en la Submeseta Sur: la provincia de Toledo". Actas del I Congreso de Arqueología de la provincia de Toledo (Toledo 1990): 125-162. Toledo.

Bueno, P.; Barroso, R. y Balbín, R. de 2007-2008: "Campaniforme en las construcciones hipogeas del megalitismo reciente al interior de la Península Ibérica". Veleia 24-24: 771-790.

Bueno, P.; Barroso, R. y Balbín, R. de 2009: "Agricultores y metalúrgicos en el Valle de Huecas (Toledo)". L. Benítez de Lugo, P. Bueno, R. Barroso, de Balbín y J. A. López Sáez (eds.): Arqueología, Medio Ambiente y Obras Públicas. El Valle de Huecas (Huecas, Toledo). Anthropos. Valdepeñas (Ciudad Real).

Bueno, P.; Barroso, R.; Balbín, R. de; Campo, M.; Etxeberría, F.; González, A.; Herrasti, L.; Treserras, J.; López, P.; López Sáez, J. A.; Matamala, J. C. y Sánchez, B. 2002: “Áreas habitacionales y funerarias en el Neolítico de la cuenca interior del Tajo: la provincia de Toledo". Trabajos de Prehistoria 59 (2): 65-79.

Carrión, J. S.; Andrade, A.; Benett, K. D.; Navarro, C. y Munuera, M. 2001: "Crossing the forest thresholds: inertia and collapse in a Holocene sequence from south central Spain". The Holocene 11: 150152.

Contreras, F. 2000: Proyecto Peñalosa. Análisis histórico de las comunidades de la Edad del Bronce del piedemonte meridional de sierra Morena y depresión Linares-Bailén. Arqueología monografías 10, Consejería de Cultura, Junta de Andalucía. Sevilla. 
Fábregas, R.; Martínez, A.; Blanco, R. y Chesworth, W. 2003: "Environmental change and social dynamics in the second-third millennium BC in NW Iberia". Journal of Archaeological Science 30 (7): 859-871.

Fagan, B. 2007: El largo verano. De la Era Glacial a nuestros dias. Gedisa. Barcelona.

Fernández-Miranda, M.; Fernández-Posse, M. ${ }^{\mathrm{a}}$ D. y Martín, C. 1993: "La Edad del Bronce en la zona oriental de La Mancha: El Acequión”. El Acequión (Albacete) y El Tolmo de Minateda (Hellín): sintesis de las investigaciones. Diputación de Albacete. Albacete: 7-27.

Fernández-Posse, M. ${ }^{\mathrm{a}}$ D.; Gilman, A., Martín, C. y Brodsky, M. 2008: Las comunidades agrarias de la Edad del Bronce en La Mancha Oriental (Albacete). Bibliotheca Praehistorica Hispana XXV, CSIC; Instituto de Estudios Albacetenses. Madrid.

Francisco, J.; Blanco, A. y López Sáez, J. A. 2006: "La transición Calcolítico-Bronce Antiguo desde una perspectiva ambiental y ambiental: el Valle de Amblés (Ávila) como referencia”. Arqueología Espacial 26: 37-56.

Galán, C. y Sánchez Meseguer, J. 1994: “Santa María del Retamar. 1984-1994”. En J. L. Sánchez Meseguer, C. Galán Saulnier y A. Caballero Klink (eds.): Jornadas de arqueología en Ciudad Real en la Universidad Autónoma de Madrid: 87-110. Toledo.

Galán, C. y Sánchez Meseguer, J. L. 2007: El Cerro de La Encantada. Asociación para el Desarrollo del Campo de Calatrava. Almagro (Ciudad Real).

García Pérez, T. 1988: "La Motilla de los Romeros (Alcázar de San Juan, Ciudad Real)". I Congreso de Historia de Castilla-La Mancha (Ciudad Real 1985) III: 13-19. Toledo.

Gibbons, A. 1993: "How the Akkadian Empire was hung out to dry". Science 261: 985-998.

Julià, R.; Riera, S. y Burjachs, F. 2001: "Holocene short events in the Iberian Peninsula based on pollen records". Terra Nostra 2001/2: 42-49.

López Sáez, J. A. 2011: “Análisis palinológico del túmulo de Los Tiesos (Mediana de Voltoya, Ávila)". Munibe 62: 283-288.

López Sáez, J. A. y Blanco, A. 2003: “La mutación Bronce Final/Primer Hierro en el suroeste de la Cuenca del Duero (Provincia de Ávila): ¿cambio ecológico y social?". En A. Esparza (ed.): Encuentro de Jóvenes Investigadores sobre Bronce Final y Hierro en la Península Ibérica. Fundación Duque de Soria-Universidad de Salamanca. Salamanca: 219-238.

Martínez Navarrete, M. a I. 1988: "Morras, motillas y castillejos: ¿unidad o pluralidad cultural durante la Edad del Bronce de La Mancha". En Homenaje a Samuel de los Santos. Instituto de Estudios Albacetenses. Albacete: 81-91.
Mejías Moreno, M., Benítez de Lugo Enrich. L.; Del Pozo Tejado, J. y Moraleda Sierra. J. (en prensa): "Los primeros aprovechamientos de aguas subterráneas en la Península Ibérica: Las motillas de Daimiel en la Edad del Bronce de La Mancha. Boletín Geológico y Minero 125, 2014.

Menotti, F. 1999: "The abandonment of the ZH-Mozartstrasse Early Bronze Age lake settlement. GIS computer simulations of the lake level fluctuation hypothesis". Oxford Journal of Archaeology 18 (2): 143-155.

Molina, F.; Nájera, T.; Aranda, G.; Sánchez-Romero, M. y Haro, M. 2005: "Recent fieldwork at the Bronze Age fortified site of Motilla del Azuer (Daimiel, Spain)". Antiquity 79: 223-235.

Montero, I.; Rodríguez, S. y Ruiz Taboada, A.1999: "La cueva-mina de La Serrana (Urda, Toledo) y su contribución al estudio del mundo funerario durante la Edad del Bronce en La Mancha". Anales Toledanos 37: 29-38.

Montero Ruiz, I.; Benítez de Lugo, L.; Álvarez García, H. J.; Palomares Zumajo, N.; Menchén Herreros, G. y Moraleda Sierra, J. (en prensa): "Cobre para los muertos. Estudio arqueométrico del material metálico procedente del monumento megalítico prehistórico Castillejo del Bonete (Terrinches, Ciudad Real-España)". Zephyrus 73: 2014, 109-132.

Murrieta-Flores, P. 2012: "Understanding human movement through spatial technologies. The role of natural areas of transit in the Late Prehistoria of South-western Iberia". Trabajos de Prehistoria 69 (1): 103-122.

Nájera, T. y Molina, F. 2004a: "La Edad del Bronce en La Mancha: problemática y perspectivas de la investigación". En L. Hernández y M. Hernández (eds.): La Edad del Bronce en tierras levantinas y zonas limitrofes. Ayuntamiento de Villena. Alicante: $531-540$.

Nájera, T. y Molina, F. 2004b: "Las motillas. Un modelo de asentamiento con fortificación central en la Llanura de La Mancha". En M. R. García Huerta y J. Morales Hervás (eds.): La Península Ibérica en el II milenio a.C.: Poblados y fortificaciones. Ediciones de la Universidad de Castilla-La Mancha. Cuenca: 173-214

Nájera, T. y Molina, F. 2004c: "Excavaciones en la Motilla del Azuer (Daimiel, Ciudad Real). 20002001". Investigaciones Arqueológicas en CastillaLa Mancha. Junta de Comunidades de Castilla-La Mancha. Toledo: 35-48.

Nájera, T.; Molina, F.; Jiménez-Brobeil, S.; Sánchez Romero, M.; Al Oumaoui, I.; Aranda, G.; Delgado Huertas, A. y Laffranchi, Z. 2010: "La población infantil de la Motilla del Azuer: un estudio Bioarqueológico". Complutum 21 (2): 69-102.

Nájera, T.; Molina, F.; Sánchez Romero, M. y Aranda, G. 2006: "Un enterramiento infantil singular en el 
yacimiento de la Edad del Bronce de la Motilla del Azuer (Daimiel, Ciudad Real)". Trabajos de Prehistoria 63 (1): 149-156.

Odriozola, C. P.; Hurtado Pérez, V.; Guerra Doce, E.; Cruz Auñón, R. y Delibes de Castro, G. 2012: "Los rellenos de pasta blanca en cerámicas campaniformes y su utilización en la definición de límites sociales". Estudos Arqueológicos de Oeiras 19, Actas do IX Congresso Iberico de Arqueometría (Lisboa 2011): 143-154.

Reimer, P. J.; Baillie, M. G. L.; Bard, E.; Bayliss, A.; Beck, J. W.; Blackwell, P. E.; BronkRamsey, C.; Buck, C. E.; Burr, G.; Edwards, R. L.; Friedrich, M.; Grootes, P. M.; Guilderson, T. P.; Hajdas, I.; Heaton, T. J.; Hogg, A. G.; Hughen, K. A.; Kaiser, K.; Kromer, B.; McCormac, F. G.; Manning, S.; Reimer, R. W.; Richards, D. A.; Southon, J. R.; Talamo, S.; Turner, C. S. M.; van der Plicht, J. y Weyhenmeyer, C. E. 2009: "IntCal09 and Marine09 radiocarbon age calibration curves, 0-50.000 years cal BP”. Radiocarbon 51 (4): 1111-1150.

Ruiz Taboada, A. 1996: “¿Qué ha pasado con la Edad del Bronce de La Mancha?”. Zephyrus 49: 211-224.
Salazar-García, D. C.; Benítez de Lugo, L.; Álvarez, H. J. y Benito, M. 2013: "Estudio diacrónico de la dieta de los pobladores antiguos de Terrinches (Ciudad Real) a partir del análisis de isótopos estables sobre restos óseos humanos". Revista Española de Antropología Física 34:6-14.

Sánchez Sánchez, J.; Benítez de Lugo, L.; Rodríguez Morales, J. y Fernández Montoro, J. L. 2012: “Nomenclatura viaria Antigua. La Vía de los Vasos de Vicarello: una Vía Augusta en Hispania". El Nuevo Miliario 15: 3-21.

Weiss, H.; Courty, M. A.; Wetterstrom, W.; Guichard, F.; Senior, L.; Meadow, R. y Curnow, A. 1993: "The genesis and the collapse of Third Millenium North Mesopotamiam Civilization". Science 261: 995-1004.

Wilkinson, T. J. 1997: "Environmental fluctuations, agricultural production and collapse: a view from Bronze Age Upper Mesopotamia". En D. Nüzhet, G. Kukla y H. Weiss (eds.): Third Millenium B.C. Climate change and Old World collapse. NATO ASI Series, Serie I, 49: 67-106. 